\title{
Going healthy: how product characteristics influence the sales impact of front-of-pack health symbols
}

\author{
Stijn Maesen ${ }^{1}$ (D) - Lien Lamey ${ }^{2} \cdot$ Anne ter Braak $^{3} \cdot$ Léon Jansen $^{4}$ \\ Received: 30 July 2020 / Accepted: 16 June 2021 / Published online: 4 September 2021 \\ (C) Crown 2021
}

\begin{abstract}
Manufacturers increasingly adopt health symbols, which translate overall product healthiness into a single symbol, to communicate about the overall healthiness of their grocery products. This study examines how the performance implications of adding a front-of-pack health symbol to a product vary across products. We study the sales impact of a government-supported health symbol program in 29 packaged categories, using over four years of scanner data. The results indicate that health symbols are most impactful when they positively disconfirm pre-existing beliefs that a product is not among the healthiest products within the category. More specifically, we find that health symbols are more effective for (i) products with a front-of-pack taste claim, (ii) lower priced products, and (iii) private label products. Furthermore, these results are more pronounced in healthier categories than in unhealthier categories. Our findings imply that health symbols can help overcome lay beliefs among consumers regarding a product's overall healthiness. As such, adding a health symbol provides easy-to-process information about product healthiness for the consumer and can increase product sales for the manufacturer.
\end{abstract}

Keywords Health symbol $\cdot$ Front-of-package nutritional information $\cdot$ Food purchases $\cdot$ Lay beliefs

One of the most important trends in grocery retailing is the growing consumer desire for healthy foods and beverages (Deloitte, 2016). The rising importance of health among consumers makes it "important for retailers and manufacturers to communicate the health benefits of foods to consumers" (Nielsen, 2017, p. 10), as consumers claim that they are "actively looking for transparency about nutrition facts" (Nielsen, 2017, p. 14). For manufacturers and retailers, this growing

Kelly Haws served as Area Editor for this article.

Stijn Maesen

s.maesen@imperial.ac.uk

Lien Lamey

lien.lamey@kuleuven.be

Anne ter Braak

a.terbraak@maastrichtuniversity.nl

Imperial College London Business School, London, UK

2 KU Leuven, Leuven, Belgium

3 Maastricht University, Maastricht, the Netherlands

4 Schuttelaar \& Partners and Scientific Secretary of the Dutch Choices Foundation, Wageningen, the Netherlands consumer health consciousness presents an opportunity to create and sustain growth in a highly competitive grocery retail environment (Financial Times, 2016). For example, in 2015, much of the growth in the U.S. consumer packaged goods industry was due to healthy foods and beverages (Boston Consultancy Group, 2016).

Manufacturers and retailers are legally obliged to include detailed nutritional information on the packages of foods, typically depicted by the well-known Nutrition Facts Panel. However, this information appears insufficient to guide consumers to healthier product choices (Balasubramanian \& Cole, 2002; Moorman, 1996). Processing and understanding detailed nutritional information remain complex tasks for many consumers (Nielsen, 2012). Moreover, this information often appears on the back side of the product package, making it time-consuming for shoppers to compare products' healthiness using the Nutrition Facts Panel (Berning et al., 2008). In response to the desire for healthy foods and beverages, manufacturers as well as retailers have adopted health symbols to communicate more clearly about the healthiness of their product offerings. Health symbols simplify nutritional information by objectively summarizing the overall healthiness (across nutrients) of a product in a way that is simple and fast to understand for consumers in an in-store environment. 
Because health symbols summarize overall product healthiness into one indicator, consumers are no longer required to integrate information on multiple nutrients to determine overall product healthiness (Talati et al., 2016). This is particularly helpful for consumers at the point of purchase (Newman et al., 2014). For example, a meta-analysis by Ikonen et al. (2020) shows that health symbols are particularly helpful for consumers to identify product healthiness (Ikonen et al., 2020).

Two types of health symbols can be distinguished. First, health symbols can be based on cross-category criteria to signal a product's healthiness across categories. Crosscategory health symbols, as such, give consumers an overall idea of the product's healthiness or unhealthiness. It could mean that all products in a category that carry the health symbol are flagged as (un)healthy. Examples of cross-category symbols are $\mathrm{NuVal}$ scores which were adopted by some retailers in the U.S., and Nutri-Scores introduced by a selection of retailers and manufacturers in France. Second, health symbols can be based on category-specific criteria to signal the healthiest products within categories. These category-specific symbols identify the healthiest products within a category, i.e., whether the product is healthier relative to other products within the same category. A category-specific symbol tends to flag only the relatively healthier products in the category (including in unhealthy categories), whereas product unhealthiness is not signaled explicitly. Examples include the Healthier Choice Symbol in Singapore, and the Choices Symbol used in countries such as the Czech Republic, Malaysia, and Nigeria.

Both cross-category and category-specific health symbol programs continue to gain popularity around the world to help consumers identify healthier products. For example, Belgium and Spain decided to adopt (cross-category) Nutri-Scores in 2018 and the Netherlands decided to introduce Nutri-Scores from mid-2021. Singapore recently introduced its (categoryspecific) Healthier Choice Symbol to categories like snacks and desserts, Indonesia adopted a (category-specific) Choices Symbol in 2019, whereas China and Vietnam are preparing to launch a (category-specific) health symbol program similar to the Choices Symbol (Choices Program, 2019).

Prior literature on health symbols is largely laboratory based and indicates that health symbols help consumers to identify healthier products and can increase purchase intentions (see Ikonen et al., 2020, for a recent meta-analysis). Two marketing studies have investigated the impact of (crosscategory) health symbols in a grocery setting, and find positive effects of health symbol use on product sales of healthy products (Dubois et al., 2021; Nikolova \& Inman, 2015). The key contribution of the current study lays in studying how the sales impact of a health symbol varies across products. This is important because the health symbol is not the only aspect of the product used by consumers to form expectations about how healthy a product is. In fact, consumers have lay beliefs about the relation between a product's overall healthiness and other aspects of the product. These lay beliefs are commonly overapplied when making decisions, even when they are not accurate (Haws et al., 2017; Mai \& Hoffmann, 2015; Raghunathan et al., 2006). For instance, the existing literature indicates that consumers have an implicit belief that tasty products, as well as cheaper products, tend to be unhealthier (Haws et al., 2017; Howlett et al., 2009), even when this is not objectively true.

Given that lay beliefs influence perceptions about overall product healthiness, and as they are not always accurate, health symbols can change existing beliefs about product healthiness. One would therefore expect an interplay between the addition of the health symbol and aspects of the product that relate to pre-existing beliefs about product healthiness. Yet, questions on how the health symbol's impact differs across products remain unanswered, and form a promising area for research (Andrews et al., 2014; Ikonen et al., 2020). Furthermore, we explore the interplay between the health symbol addition for different products in healthier versus unhealthier categories, because the importance of health is likely to differ between these categories (Dhar \& Wertenbroch, 2000). In summary, the key aim of this research is (i) to investigate how the impact of a health symbol is moderated by pre-existing beliefs about a product's overall healthiness, based on the presence of a front-of-package taste claim (e.g., creamy taste), product price, and on whether the product is a private label (vs. national brand) product, and (ii) to explore how these moderating product effects depend on the healthiness of the product category.

To answer our research questions, we study a governmentsupported interpretive summary indicator symbol called the "Choices Symbol." The Choices Symbol Program is currently active in Europe (e.g., Czech Republic), Africa (e.g., Nigeria), as well as Asia (e.g., Malaysia) (see choicesprogramme.org for a detailed overview). In each of these countries, the health symbol program uses category-specific criteria to identify the healthiest products within a product category. If a product meets these criteria, manufacturers can opt to add the health symbol front-of-pack, which signals that the product is amongst the healthiest products in the category. In this respect, the Choices Symbol Program is similar to the Healthier Choice Symbol used in Singapore, which also uses category-specific criteria to allow relatively healthier products within unhealthier categories (e.g., snacks) to carry a health symbol if they meet certain criteria.

By studying the heterogeneous impact of adding a health symbol across 29 categories (vs. 8 categories in Nikolova \& Inman, 2015; and 4 categories in Dubois et al., 2021), we provide a better understanding of the performance implications of using health symbols across different products. This has relevance for managers as well as public policy. For managers, our findings will help to make a more informed 
marketing decision when considering to add a health symbol to a product. Should one signal the healthiness of a product via a health symbol given that it is marketed as tasty? Do health symbols work better for less expensive products that are perceived to be unhealthier? Do health symbols work better for private label products than for national brands products? For public policy, we shed light on the question whether health symbols can successfully overcome inaccurate lay beliefs about product (un) healthiness that exist amongst consumers. As this is the first study on the sales impact of a health symbol program using category-specific criteria, we also empirically address policy concerns about whether the use of health symbols based on category-specific criteria leads to increased primary demand for unhealthy food categories.

\section{Theoretical background}

We first provide a brief overview of the prior literature on the effects of health symbols. Next, we provide theory to motivate novel hypotheses on how front-of-package taste claims, pricing, and the type of brand (private label vs. national brand) moderate the sales impact of health symbols, and then elaborate on why these effects may differ between healthy and unhealthy categories. Figure 1 summarizes our conceptual framework.

\section{Prior research on health symbols}

To form inferences about the healthiness of a product, consumers are influenced by health symbols because they provide an easy-to-understand front-of-package cue for overall product healthiness in a standardized format (Feunekes et al., 2008). This is because consumers generally do not have the time and/or knowledge to process detailed nutritional information such as Nutrition Facts Panels in order to evaluate and compare product healthiness (Balasubramanian \& Cole, 2002; Berning et al., 2008; Moorman, 1996). By highlighting and summarizing information from the Nutrition Facts Panel, information costs decrease and product healthiness perceptions improve (Kiesel \& Villas-Boas, 2013). This is in line with a recent meta-analytic study on mainly laboratory studies by Ikonen et al. (2020), which shows that health symbols make it easier for consumers to identify healthier products and to make healthier choices. While studies examining the impact of health symbols in a real-life setting remain scarce, two exceptions include the studies of Nikolova and Inman (2015) and Dubois et al. (2021). Nikolova and Inman (2015) use sales data on 8 product categories to show that the addition of NuVal scores (based on cross-category criteria) to a product's shelf tag leads consumers to switch to healthier products within the category. Dubois et al. (2021) use sales data on 4 product categories to show that Nutri-Scores (also based on cross-category criteria) increase sales of the healthiest products within a category (i.e., in the top third of their category nutrition-wise), but have no impact on the purchase of foods with medium, low, or unlabeled nutrition quality. Moreover, the effects using grocery data were found to be 17 times smaller compared to those found in laboratory studies, emphasizing the importance of studying health symbols in real-life grocery settings (Dubois et al., 2021).

Whereas the current literature provides insights on the effectiveness of health symbols across products, it does not provide any insights on the interplay between health symbols and other information provided on product packaging (e.g., taste claims) or product pricing. This study thereby responds to recent calls to assess "the interplay of FOP labels and other information provided on the package to help explain how consumers react to the complexity of the information provided at the point of sales" (Ikonen et al., 2020, p. 375). This is a critical issue because the health symbol is not the only aspect of the product from which consumers may derive product healthiness. For instance, the existing literature indicates that consumers have an implicit belief that tasty products, as well as cheaper products, tend to be unhealthier (Haws et al., 2017; Howlett et al., 2009), even when this is not objectively true. By studying the interplay between health symbols and the presence of product characteristics that are likely to signal product healthiness, this study answers novel questions on whether and how "perceptions of product healthfulness influence the effectiveness and outcomes related to front-ofpackage labelling" (Ikonen et al., 2020, p.375).

Fig. 1 Conceptual framework

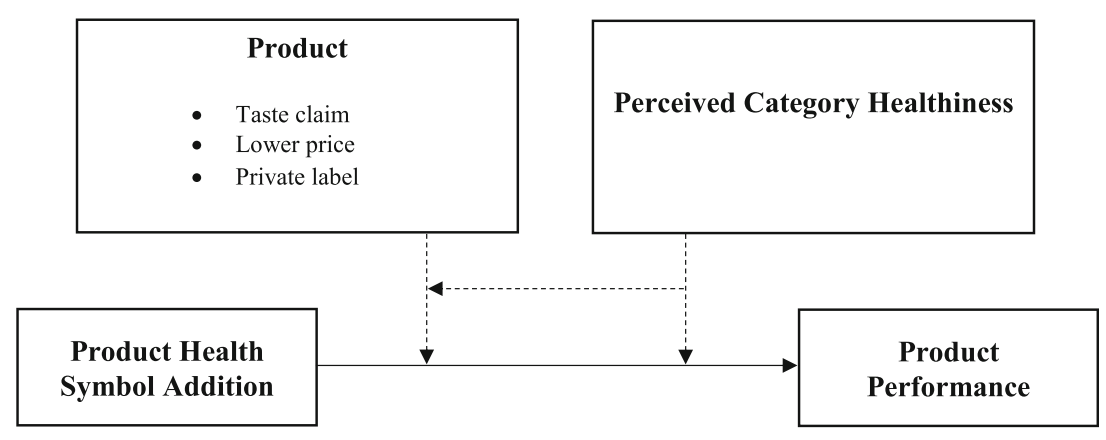


Interplay between health symbols and the presence of a taste claim, lower priced, and private label (vs. national brand) products

Lay beliefs are common-sense explanations that people use to understand their environment (Furnham, 1988; Haws et al., 2017). In a decision-making context, information on certain product attributes may be unknown or not readily available. In such instances, lay beliefs are used to form inferences about missing product attributes. It is well known that lay beliefs influence consumer decision making, even when the beliefs themselves are invalid (Alba \& Broniarczyk, 1994; Shiv et al., 2005). For instance, when assessing the strength of products, consumers are influenced by the lay belief that sustainable products (e.g., sustainable laundry detergent) are less effective (Luchs et al., 2010). Similarly, consumers may have lay beliefs about the performance of private label products. For instance, when respondents were asked to assess the capacity of AA batteries, they perceived the national brand to have higher capacity than the private label brand (Evangelidis \& Van Osselaer, 2018).

In our context, we focus on consumer lay beliefs about a product's healthiness. For instance, consumers assume a product is unhealthier simply because it is marketed as tastier (e.g., "rich taste") (Howlett et al., 2009). While lay beliefs may at times be objectively true, they are often overapplied to situations where they do not hold. Consumers rely on lay theories when information that can easily be processed is missing, and when they have little time and/or knowledge to make decisions (Haws et al., 2017). Applied to our setting, this means that consumers especially rely on the lay belief that tasty products are less healthy in the absence of easy-to-process health symbols, and when consumers are determining product healthiness in grocery store environment where they are overwhelmed by choice (Hoyer et al., 2013; Iyengar \& Lepper, 2000). Hence, prior to a health symbol addition, many consumers are likely to be influenced by lay beliefs about how healthy a product is.

We argue that the information provided by the health symbol can counter these lay beliefs among consumers (e.g., a product marketed as tastier is in fact not unhealthier). In this study, we focus on three lay beliefs among consumers regarding overall product healthiness that are identified by prior literature. Each of these lay beliefs can be disconfirmed by the addition of a health symbol. We hypothesize that the addition of a (category-specific) health symbol, which objectively signals overall product healthiness, may positively disconfirm lay beliefs about a product's existing overall healthiness perception, depending on (i) the presence of a front-of-pack taste claim, (ii) the price of the product, and (iii) whether it is a private label product. ${ }^{1}$

Expectancy-disconfirmation theory predicts that when a product's evaluation is better-than-expected (i.e., because of better overall product healthiness), or, in other words, positively disconfirms one's expectations, overall product evaluation increases, which can affect consumers' behavioral intentions (Burton et al., 2015; Grunert \& Wills, 2007; Oliver, 1980). For instance, Evangelidis and Van Osselaer (2018) find that presenting information on a feature especially increases the choice probability of the product that would have been expected to perform worse on that common feature. For example, when participants were informed that battery capacity was equal for the private label brand (initially perceived as lower in battery capacity) and the national brand, more participants chose the private label brand (Evangelidis \& Van Osselaer, 2018). Similarly, reliance on the lay belief that sustainable products are less strong, is reduced by providing product information that emphasizes the product's strength (Luchs et al., 2010). Hence, overall, based on expectancydisconfirmation theory, we predict that the impact of the health symbol addition on product performance will be stronger when the health symbol positively disconfirms consumer beliefs about the product's healthiness within the category. Next, we further elaborate on how the presence of a front-ofpack taste claim, a lower price, and a private label brand, relate to beliefs about product healthiness.

Taste claim Taste claims are verbal front-of-pack claims referring to the tastiness of the food (e.g., "deliciously rich," "full and creamy taste," "tastes great"), and are among the most prevalent claims used by the food industry (Howlett et al., 2009; Kim et al., 2009). Manufacturers make use of frontof-pack taste claims to influence the perceived tastiness of their products. However, consumers have lay beliefs regarding the relation between product tastiness and healthiness. They tend to implicitly judge tastier products to be relatively unhealthier products, even when this is objectively inaccurate (Howlett et al., 2009). Even consumers who report that they do not believe that unhealthy food is tastier, make judgements and choices as if they subscribed to such a view (Raghunathan et al., 2006). Prior to the addition of the health symbol addition, products with a taste claim were perceived as relatively unhealthier than products without a taste claim (Howlett et al., 2009). The health symbol, which objectively signals that the product is relatively healthier than other products in the

\footnotetext{
${ }^{1}$ The health symbol under investigation is voluntary (i.e., it depends on the manufacturer whether the overall healthiness is signaled to consumers) and only the healthiest products in the category are able to use the health symbol. It does not signal unhealthiness, in contrast to, for example, Nutri-Scores or NuVal Scores. As such, we do not observe cases where the health symbol addition leads to negative disconfirmation (i.e., when a product is objectively less healthy than expected).
} 
category, disconfirms the consumer's lay belief that the product with a taste claim is relatively unhealthier. Hence, based on expectancy-disconfirmation theory, we argue that the addition of a health symbol is more impactful in the presence (vs. absence) of a taste claim, because the health symbol disconfirms the lay belief that a product with a taste claim is relatively unhealthier compared to products without a taste claim in the category.

H1 A health symbol addition has a stronger sales impact for products with (vs. without) a taste claim.

Lower price Consumers also have lay beliefs regarding the relation between product pricing and healthiness. They tend to judge more expensive products as relatively healthier than cheaper products, even when this is objectively inaccurate (Haws et al., 2017; Jo \& Lusk, 2018). In other words, consumers have a "healthy = expensive intuition" (Haws et al., 2017). This "healthy $=$ expensive intuition" implies that, prior to the addition of the health symbol addition, lower priced products are perceived as relatively unhealthier than higher priced products within a category. Like the lay belief that tasty products are less healthy products, the belief that cheaper products are less healthy holds beyond to where it objectively applies. In the absence of objective and clearly interpretable nutritional information like a health symbol, consumers seeking healthy products will be less likely to select lower priced food products because they infer these products to be unhealthier. For lower priced products, the health symbol addition may offset the "healthy = expensive intuition." Based on expectancy-disconfirmation theory, we therefore hypothesize that the addition of a health symbol disconfirms the lay belief that a cheaper product is relatively unhealthier compared to more expensive products within the category.

H2 A health symbol addition has a stronger sales impact for lower (vs. higher) priced products within a category.

Private labels Consumers tend to have intuitions regarding the healthiness of private label products, as they judge private label products as unhealthier than their national brand counterparts. The presence of a private label brand on a product has been found to have a negative impact on the perceived health benefits of the product (Burke et al., 2020; Consumer Reports, 2010). However, objectively, this is not always true (Consumer Reports, 2010). The addition of a health symbol to a private label product can disconfirm the belief that private label products are unhealthier than national brand products within the category. In line with expectancy-disconfirmation theory, we expect the addition of the health symbol to be more impactful for private label products than for national brand products.
H3 A health symbol addition has a stronger sales impact for private label (vs. national brand) products.

\section{Interplay between health symbol addition, lay beliefs, and category healthiness}

Our main proposition is that the addition of health symbols will have a stronger sales impact for products with a taste claim, lower priced products, and private label products. These effects are expected to arise because of positive disconfirmation of the belief among consumers that these products are not amongst the healthiest products within their respective categories. Now, we argue that the impact of positive disconfirmation on product performance depends on the healthiness of the category. The reason for this effect can be explained by the differential importance of a product's relative healthiness within a healthy versus within an unhealthy category. Overall, the positive disconfirmation effects are expected to be stronger when the disconfirmed attribute is relatively more important in the category (Evangelidis \& Van Osselaer, 2018). Next, we first elaborate on the role of attribute importance in expectation-disconfirmation theory, and subsequently discuss how the importance of health varies between healthier and unhealthier product categories.

Attribute importance can be conceptualized as a "general assessment of the significance of an attribute for products of a certain type" (MacKenzie, 1986, p. 175). Attribute importance may be context dependent and vary across consumption decisions (Day et al., 1979; Keller, 1993). The higher an attribute's importance (e.g., the importance of health in a given category), the more weight is placed on it in consumer's decisions, and the more likely it is that the attribute drives consumer choices (Myers \& Alpert, 1968). This implies that performing better than expected on a more important attribute should have more impact than performing better than expected on a less important attribute. Although empirical evidence concerning the role of attribute importance in expectancy-disconfirmation is scarce, Evangelidis and Van Osselaer (2018) find that the beneficial effects of positive disconfirmation are larger when the underlying attribute is more important. This leads us to predict that the impact of positive disconfirmation (i.e., being healthier than expected) to be more pronounced when the importance of the attribute that is disconfirmed (i.e., relative product healthiness within the category) is higher.

In our context, the prior literature has identified that healthiness is more important in healthier than in unhealthier categories. In healthier categories, product purchases are primarily instrumental and motivated by functional aspects, such as product healthiness (Dhar \& Wertenbroch, 2000; Ramanathan \& Menon, 2006). In unhealthier categories, the hedonic goal of enjoyment dominates, and consumers are less likely to be influenced by nutritional information 
Table. 1 Examples: Health symbol category-specific criteria (per 100 g/ml, in 2010)

\begin{tabular}{|c|c|c|c|c|c|c|}
\hline Category & $\begin{array}{l}\text { Maximum } \\
\text { saturated } \\
\text { fat }(\mathrm{g})\end{array}$ & $\begin{array}{l}\text { Maximum } \\
\text { trans-fat (g) }\end{array}$ & $\begin{array}{l}\text { Maximum } \\
\text { sodium }(\mathrm{g})\end{array}$ & $\begin{array}{l}\text { Maximum } \\
\text { added } \\
\text { sugar }(g)\end{array}$ & $\begin{array}{l}\text { Minimum } \\
\text { fiber }(\mathrm{g})\end{array}$ & $\begin{array}{l}\text { Maximum } \\
\text { energy (kcal) }\end{array}$ \\
\hline Canned soup & 1.1 & 0.1 & 0.35 & 2.5 & - & 100 \\
\hline Fresh fruit juices & 1.1 & 0.1 & 0.1 & 0 & 0.3 & 50 \\
\hline Mayonnaise & 3.0 & 0.35 & 0.725 & 11 & - & 330 \\
\hline
\end{tabular}

(Balasubramanian \& Cole, 2002; Dhar \& Simonson, 1999). In line with this reasoning, health symbols have been shown to have a stronger impact on purchase intentions (Ikonen et al., 2020) and purchases (Nikolova \& Inman, 2015) in healthier than in unhealthier categories. If consumers attach less importance to the product healthiness attribute in unhealthier categories than in healthier categories, the healthiness of the category should moderate the effects of positive disconfirmation on product sales. Hence, we hypothesize that the beneficial effects of positive disconfirmation when adding a health symbol to products with a taste claim, lower priced products, and private label products, will be more pronounced in healthier than in unhealthier categories. ${ }^{2}$

H4 The positive moderating sales effect of a taste claim is stronger in healthier (vs. unhealthier) categories.

H5 The positive moderating sales effect of lower priced products within the category is stronger in healthier (vs. unhealthier) categories.

H6 The positive moderating sales effect of private label products is stronger in healthier (vs. unhealthier) categories.

\section{Method}

\section{Research setting}

To answer our research questions, we study the addition of the Choices health symbol. Specifically, we test the impact of the use of the Choices health symbol between January 2011 and September 2015 in the Dutch grocery market. This health symbol is part of the Choices Program of the Choices Foundation, which is a non-profit organization that is currently active in more than 25 countries around the world (choicesprogramme.org). Similar to the health symbol

\footnotetext{
${ }^{2}$ We do not expect positive disconfirmation to explain the moderating impact of category healthiness, as the health symbol under investigation counters lay beliefs about whether a product is among the healthiest products within a given category. As such, the health symbol does not provide any information about how products from different categories compare in terms of healthiness.
}

programs currently used in the Czech Republic, Argentina, Nigeria, Singapore, and Malaysia, the program uses category-specific criteria to identify the healthiest products within a product category (see Table 1). This means that the presence of the health symbol signals within-category product healthiness, i.e., whether the product is healthy relative to other products within the same category. The symbol is, similar to Nutri-Scores, government-supported. If a product qualifies as one of the healthier products within its category, manufacturers can opt to add the health symbol front-of-pack. The health symbol signals that the product is amongst the healthiest products in the category. This means that, in contrast to other health symbols like NuVal scores, but similar to Guiding Stars and the Healthier Choice symbol, the health symbol under investigation only labels the healthiest products. Its mere presence flags the healthiest products, but product unhealthiness is not signaled explicitly (e.g., low Nutri-Score). As the health symbol is added to products across a large set of categories (see Table 2), manufacturers can decide to signal if their product is one of the relatively healthier products within healthy but also within unhealthy categories. Next, we provide more details about the health symbol program by elaborating on (i) the foundation of the health symbol program, (ii) the health symbol program's category-specific criteria to qualify for the symbol, (iii) the visualization of the health symbol, and (iv) consumer perceptions of the health symbol.

Foundation of the health symbol program The health symbol program under investigation functions as a multi-stakeholder collaboration between the Dutch government, nutrition scientists, and several leading manufacturers and retailers, and is managed by the non-profit foundation "Ik Kies Bewust" or also called the Dutch Choices Foundation. The foundation was initially founded in 2006 by three manufacturers (Campina NV, Friesland Foods and Unilever), after government pressure for self-regulation. The Dutch government supported the symbol for many years, and the symbol was recognized by the European Commission in 2013. The health symbol program was terminated in the Netherlands in 2018 (well beyond our sample period), but continues to exist elsewhere (see section on termination below for more details). 


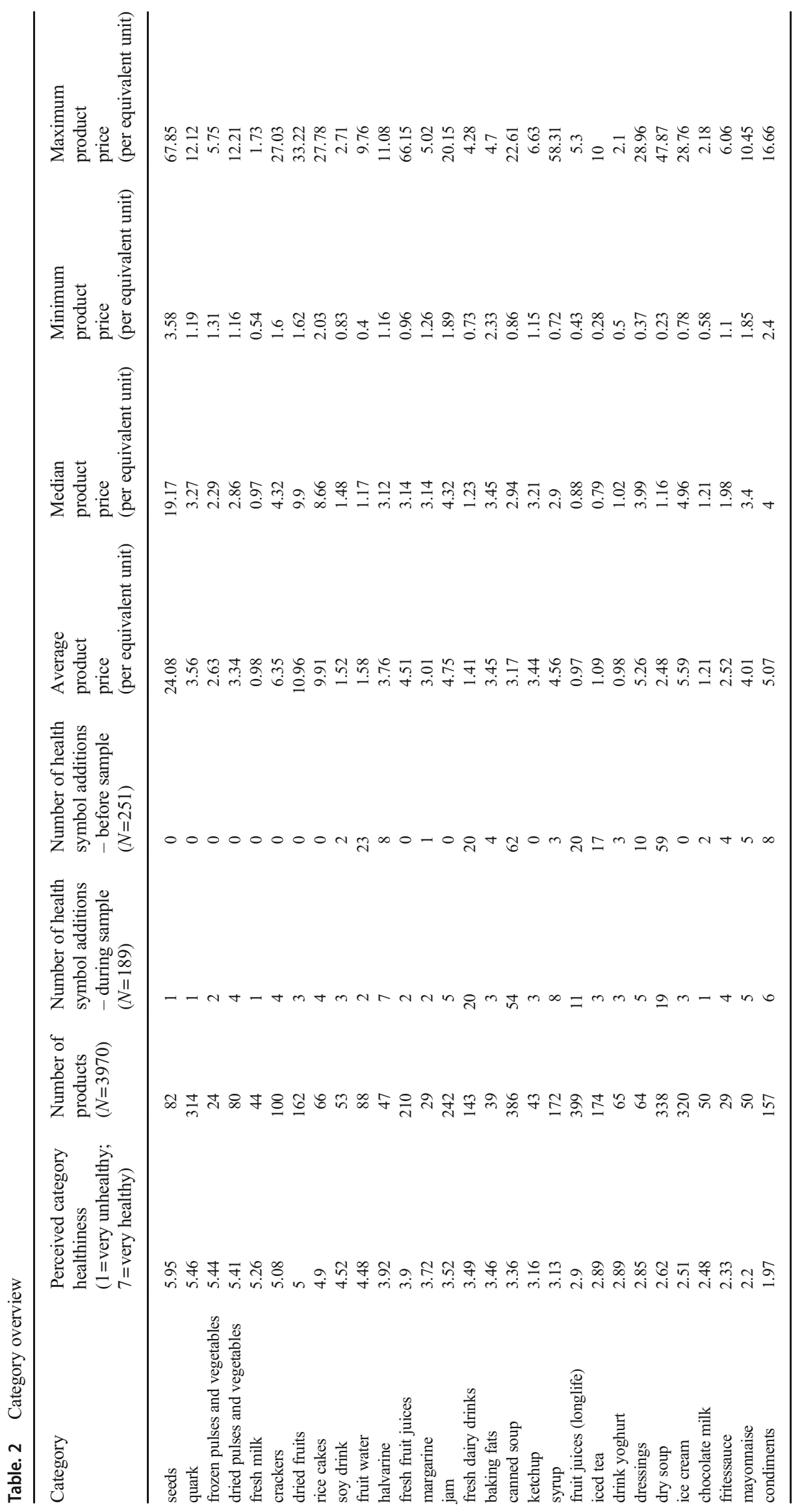


Fig. 2 Health symbol ify for the health symbol are not determined by the industry, but by a scientific committee based on international dietary guidelines. These criteria were set in a way that only the healthiest products within a category would satisfy the criteria. A scientific committee, composed of academic experts in nutrition science, set category-specific criteria to determine whether a product is relatively healthy enough within its category to use the health symbol. If a manufacturer wants to add the health symbol to a product's packaging, its product should meet these restrictive health criteria. The criteria of the Dutch Choices Foundation involve category-specific determined thresholds on saturated- and trans-fat, sodium, added sugars, fiber and calories. To qualify for the health symbol, a product must meet those thresholds on every nutrient, meaning that only the healthiest products within a category can carry the health symbol. Table 1 illustrates the criteria for a sample of categories. For instance, if a product in the category juices contains $<1.1 \mathrm{~g}$ saturated fat, $<0.1 \mathrm{~g}$ trans-fat, $<0.1 \mathrm{~g}$ sodium, no added sugar, $>0.3 \mathrm{~g}$ fiber and $<50$ cal per $100 \mathrm{ml}$, it is eligible to carry the health symbol. If a product does not comply with one of the thresholds (e.g., juice containing $<0.3 \mathrm{~g}$ fiber), it is not eligible to carry the health symbol. ${ }^{3,4}$ To avoid misuse, a third-party agency certifies that all products using the health symbol comply with the criteria. Manufacturers file an application directly at the third-party agency providing nutritional details of the product, and are, if approved, granted permission to use the health symbol. In exchange for using the symbol, manufacturers pay a yearly membership fee to cover the program's costs. The yearly fee depends on manufacturer turnover.

\footnotetext{
3 The criteria are reviewed every four to five years, at which point there may be revisions to ascertain that only the healthiest products in the category remain eligible to add the health symbol (Jansen \& Roodenburg, 2016). During our sample period (July 2011-March 2015), no such revision occurred.

${ }^{4}$ Please see https://www.choicesprogramme.org/our-work/nutrition-criteria/ for more details on the criteria for all categories.
}

B Non-basic categories ${ }^{b}$

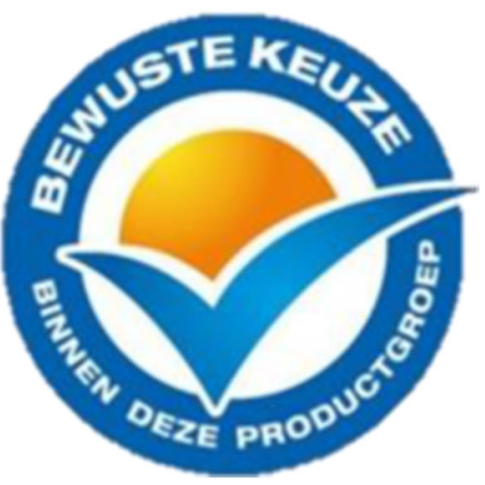

Health symbol visualization While the health symbol is applicable to all (non-baby) foods and (non-alcoholic) beverages, the program makes a distinction between basic categories (e.g., dairy) and non-basic categories (e.g., soup, snacks, sauces). Whether a category is basic or not depends on whether it belongs to one of five "basic" food groups in the Dutch Food Pyramid ("Schijf van Vijf" in Dutch). The five basic food groups are (i) vegetables and fruits, (ii) bread, pasta, seeds, potatoes, (iii) dairy, meat, fish, egg, meat replacement, (iv) fats and oils, and (v) water.

The symbol, visualized as a blue tick mark inside a circle (see Fig. 2), is placed front-of-pack. Whereas the tick mark is blue for both basic and non-basic categories, basic categories feature a green circle around the blue tick mark accompanied by the text "healthy choice within this product group" (Fig. 2, Panel A), whereas non-basic categories feature a blue circle around the blue tick mark accompanied by the text (health) "conscious choice within this product group" (Fig. 2, Panel B). Except for these color and phrasing differences between basic and non-basic food categories, the health symbol is standardized across products and categories, and manufacturers need to adhere to strict guidelines on the size and placement of the symbol. For instance, a minimum and maximum size for the symbol is determined depending on the size of the facing of the package. Note that in our analyses, we will control for potential heterogeneity in impact between the symbol in basic and non-basic categories.

Consumer's perceptions of the health symbol One year after the launch, $88.4 \%$ of the Dutch population was familiar with the symbol (Vyth et al., 2009). During our sample period the aided awareness for the health symbol remained high and stable (around 90\%) as shown by a yearly GfK survey amongst Dutch grocery shoppers $(\mathrm{N} \approx 1000$ per year). Moreover, survey results among consumers $(N=1057)$, representative for the Dutch population, indicate that $88 \%$ of the 
consumers know that the criteria that determine whether a product is eligible to add the health symbol are not set by manufacturers themselves (Consumentenbond, 2016). Similar to other health symbols (e.g., NuVal), this enhances the credibility of the health symbol program.

To educate consumers on the fact that the health symbol flags relatively healthier products within a given category, the health symbol explicitly states this within-category designation in the symbol notation. Moreover, following the introduction of the health symbol in 2006, its launch was supported by mass media awareness campaigns to further inform consumers on the interpretation of the symbol. To further ascertain that consumers actually perceive the focal health symbol as an indicator of a product's relative healthiness within the category rather than across categories, we conducted a smallscale experiment in which respondents were randomly assigned to either a condition in which they viewed products with our focal (category-specific) health symbol, or to a condition in which they viewed the same products but now with a cross-category health symbol (i.e., Nutri-Scores). The design, product images, and measures used in this experiment can be found in the Appendix. The results of this study provide empirical support for the notion that our focal category-specific health symbol is significantly more likely to improve consumer's perceptions of the within-category healthiness of the product compared to a cross-category health symbol, whereas the cross-category health symbol was significantly more likely to improve consumer's perceptions of cross-category healthiness compared to the category-specific health symbol (see Appendix for a detailed description of the results).

Health symbol termination Despite offering consumers a simple way to identify products that are overall healthier, health symbols have been criticized for oversimplifying nutritional information across multiple nutrients into a single indicator, thereby possibly misleading consumers. As a result, health symbols are sometimes discontinued. For instance, the $\mathrm{NuVal}$ rating system was phased out in 2017 (Food Navigator, 2017). In our setting, the use of category-specific criteria raised concerns that consumers would view relatively healthier products in unhealthier categories as healthy products overall. Following a campaign launched in March 2016 by the Dutch consumer organization that mediatized this source of criticism, the Dutch government decided, roughly 10 years after the health symbol program had been launched, that the health symbol should be removed from product's packaging in all categories by October 18th, 2018 (Distrifood, 2016). However, we found no evidence in consumers' actual purchase behavior in support of these concerns, as the adoption of the category-specific health symbol did not lead to an increase in primary demand in unhealthier categories (see "follow-up analysis" in the Results Section for more details on this analysis), but rather makes consumer choose a relatively healthier alternative within the category. The timing of the decision to terminate the program (October 2016), the media campaign criticizing the health symbol preceding this decision (starting March 2016), and the actual removal from packages (between October 2016 and 2018), took place after our sample period (which ends in September 2015), thereby not influencing the results presented in this study. Even though the Choices program has been discontinued in the Netherlands, it has, to the best of our knowledge, not been cancelled in any other country. As such, other countries using the health symbol program under investigation (e.g., Czech Republic, Argentina, Nigeria) continue to do so, and comparable health symbol programs with category-specific criteria continue to exist elsewhere (e.g., Singapore's Healthier Choice Symbol). Furthermore, several countries are planning to introduce a health symbol program using category-specific criteria (e.g., China, Vietnam) (Choices Program, 2019).

\section{Data}

Scanner data Weekly store-level scanner sales data at the SKU-level including promotion and price information are obtained from Information Resources Incorporated (IRI). The scanner data range from January 2011 to September 2015 and include all (i.e., 806) store outlet sales from the top five traditional retailers in six (out of twelve) adjacent regions in the Netherlands, all situated in the middle and northern part of the country. ${ }^{5}$ The five retailers are Albert Heijn (417 stores), Jumbo (211 stores), Plus (85 stores), Coop (73 stores), and Hoogvliet (20 stores), covering $66 \%$ of total grocery sales. We cover all (i.e., 29) categories in which a health symbol addition takes place within this time period and include the top five brands (in terms of volume sales) per category at each of the five retailers. ${ }^{6}$ As a result, our dataset includes a set of 207 brands across 29 categories, and covers all health symbol additions within those categories. The categories range from dairy products (e.g., drink yoghurts), beverages (e.g., juices), fruits and vegetables (e.g., dried fruits, frozen vegetables), spreads (e.g., jam), sauces (e.g., ketchup), to oils and fats (e.g., margarine) and snacks (e.g., ice cream). On average, 6.52 products per category added a health symbol $(\mathrm{SD}=$ 10.24), which corresponds to $5.59 \%$ of the total number of products offered in a category $(\mathrm{SD}=4.30 \%)$. Table 2 provides an overview of the 29 categories, the number of additions per category, and several other descriptive statistics on these categories.

The selected brands provide good coverage of category sales and capture, on average, $90 \%$ of volume sales (SD =

\footnotetext{
${ }^{5}$ Note that IRI does not cover household level purchases in the Netherlands (see Limitations section for more details).

${ }^{6}$ Note that all retailers offer the 29 categories.
} 
$9 \%$, MIN $=70 \%$, MAX $=99 \%)$ in the category. While we focus on the top five brands, we observe both major brands, as well as minor brands. The average brand has $12 \%$ market share $(\mathrm{SD}=12 \%, \mathrm{MIN}=0.05 \%, \mathrm{MAX}=76 \%) .39 \%$ of the brands are minor brands with a market share below $5 \%$ (Geyskens et al., 2010). ${ }^{7}$ Because (i) the health symbol is added simultaneously to all packaging sizes of the same product (e.g., all packaging sizes of Kellogg's Special K Raspberry), and (ii) an examination of the effects on the SKU level did not reveal any differences in the sales impact of adding a health symbol depending on the size of the SKU's packaging, we aggregate different SKUs that are nutritionally equivalent to one "product" (i.e., we aggregate across different packaging sizes). Next, because we are interested in marketlevel changes in product performance following the addition of the health symbol, we aggregate sales of those products across all stores from the top five retailers in the market. To aggregate product-level marketing mix variables across SKUs and then across stores, we first compute weighted averages across an SKU's different packaging sizes, using as weights the SKU's share of volume sales in the store using a rolling window of the previous quarter (13 weeks). Then, we aggregate from the store to the market level, with weights equal to each store's share of total category volume sales in the same rolling window (Datta et al., 2017). In line with previous research using IRI data, a product is assumed to be available in a store in week $t$ if it has non-zero sales at least once in the most recent four weeks $(t, t-1, t-2, t-3)$ (Datta et al., 2017).

In total, the data cover 3970 products. Out of those 3970 products, we observe 189 health symbol additions during our sample period, while 251 products had already added the symbol at the start of our data. The set of 189 additions covers 29 brands (including five private label brands) owned by 16 different manufacturers. All 16 manufacturers already used the health symbol prior to 2011, but extended the use to additional products in the period after 2011.

Nutritional data To determine whether products are eligible to add the health symbol, nutritional information is used. Nutritional data are obtained from several sources, such as the Dutch Choices Foundation (11\% of the 3970 products), PS in Foodservice (i.e., a Dutch organization that gathers product information from manufacturers such as nutritional information) (15\%), websites of Dutch grocery retailers $(61 \%)$, and, where unavailable, through other websites listing nutritional information for consumers (13\%). Out of the 3970

\footnotetext{
7 The focus on this selection of brands is further motivated by the substantial unavailability of nutritional data for products from lower ranked brands. However, we observe no health symbol additions for products from brands not included in our selection, meaning that we do not exclude any health symbol additions from our dataset by focusing on the top five brands. Controlling for the average market share of a brand (in the first year of the sample period) in the analysis, did not change our results.
}

products in our dataset, $31 \%(N=1213)$ is eligible to add the health symbol. By the end of our sample period, $36 \%$ of the eligible products (i.e., $(189+251) / 1213)$ had added the health symbol, meaning 773 eligible products did not add the health symbol.

\section{Measurement}

Product performance We measure product performance as the volume sales (in equivalent units, i.e., per $100 \mathrm{~g} / \mathrm{ml}$ ) for a given product in a given category in a given week (Nikolova \& Inman, 2015).

Health symbol addition he effect of the health symbol addition is captured by a step dummy variable that equals 1 from the week onwards that the symbol is added to the product, and 0 otherwise (Nikolova \& Inman, 2015). Information on the timing (week) of the health symbol addition is obtained through the Dutch Choices Foundation. The timing is based on the week of certification by the third-party certification agency, and additions took place at various points in time across $2011(N=7), 2012(N=32), 2013(N=81), 2014$ $(N=66)$ and $2015(N=3)$.

Taste claim, lower price, and private label products We use three dummy variables to indicate the presence of a taste claim, lower priced products, and whether it concerns a private label product. Products with a taste claim are products with a front-of-pack claim referring to the taste of the food (e.g., superior taste, rich taste). To obtain information on the presence of a taste claim, we collected product images of all products that added the health symbol $(N=189)$ during our observation period. These product images are used to manually code whether a product contains a taste claim. These images were obtained through websites of retailers and websites stocking retailer promotion folders. Lower priced products are products priced below the median equivalent (regular) unit price within the category. ${ }^{8,9}$ The prices are calculated on the first 26 weeks the product is observed in the sample. Products are classified as private label products by IRI. We use effect coding for the three dummy variables (i.e., 1 for products with a taste claim, those with a lower price, private label products, respectively, and -1 otherwise). The descriptive statistics indicate that, among the products that feature a health symbol $(N=189), 17.1 \%$ features a

\footnotetext{
${ }^{8}$ On average, lower priced products (classified based on median category prices on the market level) can also be considered as lower priced in $93.13 \%$ of the stores (i.e., below the median category price on the store level) in which they are available.

${ }^{9}$ The same substantive findings are obtained if we classify products as lower priced when their price is below the average equivalent unit price within the category.
} 
taste claim, $29.6 \%$ has a lower price, and $32.3 \%$ are private label products.

Perceived category healthiness We measure perceived category healthiness among a sample of Dutch households $(N=60)$. The average age of the participants is representative for the Dutch population $(\mathrm{M}=44.11, \mathrm{SD}=13.89, \mathrm{MIN}=$ 20 , MAX = 73). Perceived healthiness is measured using the item "How healthy is this category to you" on a 7-point scale ( 1 = very unhealthy, 7 = very healthy) (cf. Feunekes et al., 2008). The average perceived category healthiness equals 3.75 on a 7 -point scale ( 1 = very unhealthy; 7 = very healthy $)$ $(\mathrm{SD}=1.16, \mathrm{MIN}=1.97, \mathrm{MAX}=5.95)$. The survey results show substantial face validity. Examples of categories perceived as unhealthy are mayonnaise $(\mathrm{M}=2.20)$, ice cream $(\mathrm{M}=2.51)$ and iced tea $(\mathrm{M}=2.89)$. Categories perceived as healthy are frozen vegetables $(\mathrm{M}=5.44)$, dried vegetables $(\mathrm{M}=5.41)$ and fresh milk $(\mathrm{M}=5.26)$. Categories perceived as neither very healthy nor very unhealthy, are categories such as canned soup $(\mathrm{M}=3.36)$, jam $(\mathrm{M}=3.52)$ and margarine $(\mathrm{M}=3.72)$.

Control variables First, we control for two category-level variables that may influence the impact of adding a health symbol. Health symbol penetration controls for the share of products in the category that feature the health symbol in a given week. On average, across all products within a category, $11 \%$ of the products within a category feature the health symbol in a given week $(\mathrm{SD}=10 \%, \mathrm{MIN}=0.5 \%, \mathrm{MAX}=39 \%)$. To differentiate between what the Choices Foundation classifies as basic vs. non basic categories (see Research Setting), we include a dummy variable that equals 1 for basic categories and - 1 for non-basic categories. Second, we account for the presence of a front-of-pack nutrition content claim (e.g., reduced fat). Nutrition content claims "use terms such as "free", "low', or "reduced" to describe the amount of fat, sugar or sodium" (Cao and Yan, 2016, p. 58). Out of the 189 products with a health symbol, $37.8 \%$ featured a nutrition claim. Third, we account for the product's own and competitor's marketing mix, by including the ratios of own to competitive (volumeweighted) regular price, feature/display intensity, price promotions, and distribution. Fourth, we include a deterministic trend.

Table 3 contains more details on the operationalizations. Pairwise correlations between all covariates do not exceed .7, indicating that multicollinearity is not a major concern in the estimation.

\section{Model specification}

To quantify the main impact of a health symbol addition on product performance and the moderating impact of taste claim, lower price, private label products and perceived category healthiness, we use the following regression model (Equation 1).

$$
\begin{aligned}
\text { Sales }_{\text {ict }}=\beta_{0 \mathrm{ic}} & +\beta_{1} \text { Addition }_{\mathrm{ict}} \\
& +\beta_{2} \text { Addition }_{\mathrm{ict}} \times{\text { Taste } \text { claim }_{\mathrm{ic}}} \\
& +\beta_{3} \text { Addition }_{\mathrm{ict}} \times \text { Lower price }_{\mathrm{ic}} \\
& +\beta_{4} \text { Addition }_{\mathrm{ict}} \times \text { Private label }_{\mathrm{ic}} \\
& +\beta_{5} \text { Addition }_{\mathrm{ict}} \times \text { Perceived category healthiness }_{\mathrm{c}} \\
& +\beta_{6} \text { Addition }_{\mathrm{ict}} \times \text { Taste claim }_{\mathrm{ic}} \times \text { Perceived category healthiness }_{\mathrm{c}} \\
& +\beta_{7} \text { Addition }_{\mathrm{ict}} \times \text { Lower price }_{\mathrm{ic}} \times \text { Perceived category healthiness }_{\mathrm{c}} \\
& +\beta_{8} \text { Addition }_{\mathrm{ict}} \times \text { Private label }_{\mathrm{ic}} \times \text { Perceived category healthiness }_{\mathrm{c}} \\
& +\Delta \text { Control variables }+\epsilon_{\mathrm{ict}}
\end{aligned}
$$

Sales $_{\text {ict }}$ reflects the $\ln$-transformed sales of product $i$ in category $\mathrm{c}$ in week t. $\beta_{0 \text { ic }}$ represents a fixed effect per product to account for unobserved product effects. The product fixed effects control for the main effect of the time-invariant moderators (i.e., taste claim, lower price, private label, and perceived healthiness) on sales, and for any other time-invariant product effects that may drive sales. Addition $_{\text {ict }}$ is a step dummy that equals 1 from the week onwards that the health symbol is added to the product, and captures the impact of the health symbol addition on product sales. We include the interaction terms that capture the moderating effect of the taste claim, lower price and private label indicators $\left(\beta_{2}-\beta_{4}\right)$, perceived category healthiness $\left(\beta_{5}\right)$, and the three-way interactions terms $\left(\beta_{6}-\beta_{8}\right) . \Delta$ is the vector of coefficients for the control variables (see Measurement Section and Table 3 for details). The Addition $_{\text {ict }}$ variable captures the main effect of adding a health symbol addition for the set of products that does so within our sample. Via the inclusion of product fixed effects, the main effects of our time-invariant moderators at the product (taste claim, lower price, private label) and category level (perceived healthiness) on sales are controlled for. The same holds for the main effects of our product and category level control variables. Note that while the inclusion of (lower level) product fixed effects automatically controls for (higher level) category fixed effects, health symbol penetration is a time specific control variable and is therefore included as a main effect in Equation 1.

In line with Sotgiu and Gielens (2015) and Lamey et al. (2012), we add an autoregressive residual term to account for autocorrelation due to the time-series nature of the data. The presence of first-order autocorrelation is confirmed by a Durbin-Watson test, and based on this test and model fit (AIC, cf. Judge et al., 1988) a first-order autoregressive term is included in Equation 1. ${ }^{10}$ The dependent variable and all continuous independent variables are ln-transformed before estimation. We used effect coding for binary moderating

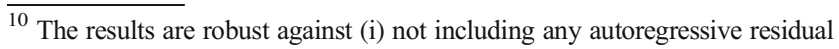
and (ii) including a second-order autoregressive residual.
} 
Table. 3 Operationalizations

\begin{tabular}{|c|c|}
\hline Variable & Operationalization \\
\hline Sales $_{\text {ict }}$ & Volume sales (in equivalent units) of product $\mathrm{i}$ in category c in week t (Nikolova \& Inman, 2015). \\
\hline Addition $_{\text {ict }}$ & $\begin{array}{l}\text { Step dummy that takes the value of } 1 \text { from the week onwards that the health symbol is added to product } i \text { in category } c \text {, and } \\
0 \text { otherwise (Nikolova \& Inman, 2015). }\end{array}$ \\
\hline \multicolumn{2}{|l|}{ Product } \\
\hline Taste claim $_{\text {ic }}$ & $\begin{aligned}= & 1 \text { for products with a taste claim, }-1 \text { otherwise. A product is classified as containing a taste claim if it has a front-of-pack } \\
& \text { claim referring to the taste of the food (e.g., superior taste, rich taste). }\end{aligned}$ \\
\hline Lower price $_{\text {ic }}$ & $\begin{aligned}= & 1 \text { for products priced below the median equivalent (regular) unit price (calculated across the first } 26 \text { weeks the product is } \\
& \text { observed in the sample) across all products in category c, }-1 \text { otherwise. }\end{aligned}$ \\
\hline Private label $_{\text {ic }}$ & $=1$ for private label products, -1 otherwise. Products are classified as private label products by IRI. \\
\hline \multicolumn{2}{|l|}{ Category } \\
\hline $\begin{array}{l}\text { Perceived category } \\
\text { healthiness } \mathrm{c}_{\mathrm{c}}\end{array}$ & $\begin{array}{l}\text { Measured using the item "How healthy is this category to you?" on a 7-point scale }(1=\text { very unhealthy, } 7=\text { very healthy) } \\
\text { (Feunekes et al., 2008). The data are based on a survey among Dutch consumers }(N=60) \text {. }\end{array}$ \\
\hline \multicolumn{2}{|l|}{ Control } \\
\hline \multicolumn{2}{|l|}{ Category-level } \\
\hline Health symbol penetration $_{\mathrm{ct}}$ & Share of incumbent products that feature the health symbol in category $\mathrm{c}$ in week $\mathrm{t}$. \\
\hline Basic category $_{c}$ & $=1$ for (basic) categories in which a green circle is used, -1 for (non-basic) categories in which a blue circle is used. \\
\hline \multicolumn{2}{|l|}{ Product-level } \\
\hline Nutrition claim $_{\text {ic }}$ & $\begin{aligned}= & 1 \text { for products with a nutrition claim, }-1 \text { otherwise. A product is classified as containing a nutrition claim if it has a } \\
& \text { front-of-pack nutrition claim (e.g., light, reduced fat). }\end{aligned}$ \\
\hline Relative regular price $_{i c t}$ & $\begin{array}{l}\text { Ratio of the own and competitive (product and store volume-weighted) regular equivalent unit price for product } \mathrm{i} \text { in } \\
\text { category } \mathrm{c} \text { in week t. }\end{array}$ \\
\hline $\begin{array}{l}\text { Relative feature/display } \\
\text { intensity }\end{array}$ & $\begin{array}{l}\text { Ratio of the own and competitive (product and store volume-weighted) number of product feature and/or display dummies } \\
\text { for product } i \text { in category c in week } t \text {. }\end{array}$ \\
\hline Relative price promotion ${ }_{\text {ict }}$ & $\begin{array}{l}\text { Ratio of the own and competitive (product and store volume-weighted) percentage price reduction off the regular price for } \\
\text { product i in category c in week } t \text {. }\end{array}$ \\
\hline Relative distribution $_{\text {ict }}$ & 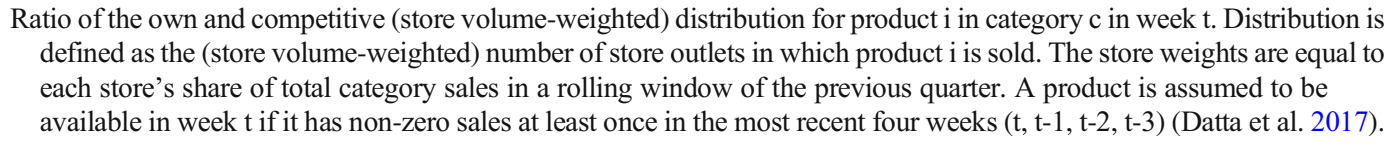 \\
\hline Trend $_{t}$ & Deterministic trend variable \\
\hline
\end{tabular}

variables (taste claim, lower price and private label) and grand mean-centering for continuous moderating variables. As such, the parameter for the health symbol addition (Addition ${ }_{i c t}$ ) reflects the average impact of adding a health symbol on product sales. Equation 1 is estimated as a panel regression model on all products that add the health symbol $(N=189)$ and all products that chose to not add the health symbol within our sample period, despite being eligible to add the symbol $(N=$ $773)$. This results in a total set of $962(189+773)$ products in the estimation sample.

\section{Endogeneity}

Health symbol addition The decision by manufacturers to add a health symbol might be endogenous because this decision may be dependent on the product, category and/or manufacturer. In addition, the timing of the addition may not be random either. In line with current recommendations to deal with endogeneity, we first exploit the panel structure of our data and control for unobserved product effects in Equation 1
(Germann et al., 2015; Papies et al., 2017). ${ }^{11}$ Despite controlling for unobserved product effects, it may still be that health symbol additions are set based on demand shocks that vary across cross-sections and time. In other words, it is possible that there are (time-specific) unobserved variables that are correlated with the health symbol addition decision as well as sales. Failure to address this issue, may result in biased estimates. To address this source of endogeneity, we follow recent studies in marketing (Arora et al., 2017; Danaher et al., 2015; Sridhar et al., 2016), and use the control function approach (Petrin \& Train, 2010). Thus, we (i) estimate a probit model where the dependent variable is the health symbol addition step dummy variable, (ii) compute for each observation the predicted probability that the product features the health symbol at time t, (iii) subtract the predicted probability from the actual addition of the health symbol, and (iv) include this probit residual as an additional explanatory variable in Equation 1. The auxiliary

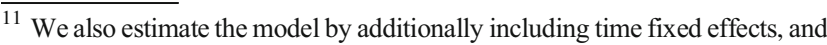
obtain the same substantive findings.
} 
regression model is given by Equation 2 .

$$
\begin{aligned}
\operatorname{Prob}\left(\text { Addition }_{\mathrm{ict}}=1\right)= & \gamma_{0 \mathrm{~m}} \\
& +\gamma_{1} \text { Perceived category healthiness }_{\mathrm{c}} \\
& +\gamma_{2} \text { Health symbol penetration }_{\mathrm{ct}} \\
& +\gamma_{3} \text { Basic category }_{\mathrm{c}}+\gamma_{4} \mathrm{IV} 1_{\mathrm{ct}} \\
& +\gamma_{5} \mathrm{IV} 2_{\mathrm{mct}}+\mathrm{e}_{\mathrm{ict}}
\end{aligned}
$$

Equation 2 is estimated as a probit model, where the dependent variable is Addition $_{\text {ict }}$ from Equation 1. It is estimated on all products that add the health symbol $(N=189)$ and all products eligible to add the health symbol that have not yet done so by the beginning of our sample $(N=773)$. Note that the product fixed effects specification in Equation 1 already picks up time-invariant sources of (unobserved) product heterogeneity. This places less burden on this control function, because it does not serve to condition out cross-sectional sources of unobserved, time-invariant variation that may correlate with the error term (Sridhar et al., 2016). Equation 2 contains manufacturer fixed effects that capture heterogeneity between manufacturers $\left(\gamma_{0 \mathrm{~m}}\right),{ }^{12}$ and the category characteristics from Equation 1 (i.e., perceived category healthiness, health symbol penetration and basic category).

To address potential endogeneity concerns due to unobserved variables that are correlated with the health symbol addition decision as well as sales, Equation 2 needs to be extended with suitable instrumental variables (IVs), that are relevant (i.e., able to predict the health symbol addition decision strongly enough), and that satisfy the exclusion restriction (i.e., should not directly affect sales once the health symbol addition variable and other observed variables are controlled for). We include two instrumental variables: (i) the share of available products in the category eligible to add the health symbol (IV1) and (ii) the share of incumbent manufacturers' products using the health symbol in non-focal categories (IV2). The share of available products eligible to add the health symbol (IV1) may influence the manufacturer's decision to add the symbol, because the more products are eligible to add the health symbol, the less likely the manufacturer may be to add the health symbol. The underlying reasoning is that the health symbol presents a less sustainable competitive advantage in categories where more products are eligible to add the health symbol, since competitor products can simply respond by adding the health symbol to their products as well. IV1 is not expected to influence manufacturer's product performance, because eligibility is not observed by consumers. For IV2, we use, in line with common practice in the literature,

\footnotetext{
$\overline{12}$ Estimating Equation 2 with product (rather than manufacturer) fixed effects does not change our conclusions.
}

competitor's decisions as instruments (Dinner et al., 2014; Germann et al., 2015; Keller et al., 2016). More specifically, we use information on decisions from incumbent manufacturers, in other product categories (Gijsenberg, 2014; Van Heerde et al., 2013). IV2 captures the share of products from incumbent manufacturers in categories other than the focal category that feature the health symbol. As an example, if manufacturer $\mathrm{X}$ is active in category $\mathrm{Y}$, and its competitors have a total assortment of 1000 products across categories outside category Y, out of which 100 feature the health symbol, IV2 equals 0.10 for manufacturer $\mathrm{X}$ in category $\mathrm{Y}$. The logic is that decisions made by incumbent manufacturers in other product categories are likely to be unrelated to demand for products by the focal manufacturer in the focal category, but that they may influence the probability that the focal manufacturer adopts the health symbol in the focal category.

We address the recommended key elements to assess instrument strength (Papies et al., 2017), by providing insights into the fit of the auxiliary regression without versus with IVs, and formally assess the incremental fit. First, when we include the IVs, both instruments have a significant impact ( $p$-values $<.05$ ) on the probability of adding the health symbol, suggesting that they indeed have a strong impact on health symbol additions (see Table 4 for detailed estimation results of Equation 2). Second, following the recommendation of Rossi (2014), we determine whether there is a significant improvement in the fit of the model by estimating Equation 2 twice: once by including and once by excluding the instruments. Based on the AIC, the model including the instruments performs better. The results of a Likelihood Ratio Test confirm that the first-stage model has a significantly better fit than the model without it $\left(\chi^{2}(1)=672.47, p<.001\right)$ (Arora et al., 2017). Third, we run an incremental F test (based on an OLS) to test for the explanatory power of these independent variables. The instruments were sufficiently strong, as the incremental F-value exceeded common threshold of $10(\mathrm{~F}=107$, $p<.01$ ) (Sotgiu \& Gielens, 2015). Thus, we conclude that the instruments are not weak. We include the control function correction term in Equation 1 to address the endogeneity of the health symbol addition variable.

Marketing mix In line with recent studies in marketing (e.g., Gielens et al., 2018; Guitart et al., 2018; Lim et al., 2018), we adopt Park and Gupta's (2012) Gaussian copulas to account for the potential endogeneity of the four marketing mix variables, which is the most feasible approach in a setting with multiple brands and categories like ours (Rutz \& Watson, 2019). More specifically, we add a copula for weekly relative regular price, relative feature/display intensity, relative price promotion and relative distribution in Equation 1. The Gaussian copula for each of these variables $X_{\text {ict }}$ for product $i$ in category $\mathrm{c}$ in week $\mathrm{t}$ is defined as: Copula $\mathrm{ict}_{\mathrm{i}}=\Phi^{-1}(\mathrm{H}$ $\left(\mathrm{X}_{\mathrm{ict}}\right)$ ), where $\Phi^{-1}$ is the inverse of the cumulative normal 
Table. 4 Results: Health symbol addition (Eq. 2)

\begin{tabular}{lcc}
\hline Variable & Estimate & SE \\
\hline Manufacturer fixed effects & Included & \\
Perceived category healthiness $\left(\gamma_{1}\right)$ & -.757 & .947 \\
Health symbol penetration $\left(\gamma_{2}\right)$ & $1.02 * * *$ & .098 \\
Basic category $\left(\gamma_{3}\right)$ & $-.201^{*}$ & .107 \\
IV1 $\left(\gamma_{4}\right)$ & $-1.199^{* *}$ & .606 \\
IV2 $\left(\gamma_{5}\right)$ & $24.967^{* * *}$ & 3.618 \\
Hit ratio (overall) & .91 & \\
Hit ratio (1-values) & .93 & \\
Pseudo-R & .68 & \\
\hline
\end{tabular}

$* * * p<.01, * * p<.05, * p<.10$, (two-sided)

All VIF values are below $10($ MAX $=4.24)$

distribution function, and $\mathrm{H}($.$) the empirical distribution of the$ respective reaction variable (Park \& Gupta, 2012). For identification purposes, each variable should be non-normally distributed, which is confirmed by a Shapiro-Wilk test (all $p$ values $<.01)$.

\section{Estimation}

We standardize the (ln-transformed) dependent variable and independent variables that vary across products and time within product to control for the product fixed effects (Ataman et al., 2010). This approach avoids having to estimate a large number of product fixed effects and facilitates comparison across products and categories, and implies that the model uses within-product variation over time for inferences (Ataman et al., 2010). Note that this approach is equivalent to actually estimating the product fixed effects (Papies et al., 2017). ${ }^{13}$ Equation 1 is estimated using robust standard errors clustered at the category level.

\section{Results}

\section{Health symbol additions}

Results for the auxiliary regression Equation 2 appear in Table 4. The maximum VIF factor for this equation is 4.24 . The set of independent variables explains the decision to add

\footnotetext{
13 The within-transformation does technically not preclude the estimation of main effects of time-invariant characteristics (e.g., basic vs. non-basic categories). Their coefficients would capture whether there is, on average, more vs. less over time variation in sales depending on the characteristic (e.g., whether there is more over-time variation for basic than for non-basic categories). However, over-time variation is already captured on the product level by the deterministic trend. Including time-invariant characteristics in Equation 1 (lower price, private label, perceived category healthiness and basic category), results in the same substantive findings.
}

the health symbol accurately, as we obtain an overall hit rate of $91 \%$, and $93 \%$ of the actual 1 values (i.e., instances where the health symbol addition variable equals 1 ) are accurately classified as 1 by the model. The results indicate that health symbol additions are not dependent on the perceived category healthiness $\left(\gamma_{1}=-.757, p=.80\right)$, but are more likely in categories where more products already feature the symbol $\left(\gamma_{2}=1.02, p<.01\right)$, and less likely in basic categories $\left(\gamma_{3}\right.$ $=-.201, p<.10)$. Furthermore, both IVs are significant, meaning that manufacturers are less likely to add the health symbol when more products are eligible to add the health symbol $\left(\gamma_{4}=-1.199, p<.05\right)$, and more likely to add the health symbol when incumbent manufacturers in non-focal categories use the health symbol $\left(\gamma_{5}=24.967, p<.01\right)$. The hit rate and the face validity of the parameter estimates provide support for the validity of the health symbol addition equation.

\section{Impact of a health symbol addition on product performance}

First, we gain model-free insights into the impact of adding a health symbol on product performance by comparing the raw mean weekly sales before and after the addition of a health symbol. Post-addition sales were on average $4.58 \%$ higher compared to pre-addition sales $(t=2.95, p<.01)$. The increase is stronger in healthier categories (i.e., categories scoring above the median value for perceived category healthiness) $(+8.15 \%)$ than in unhealthier categories $(+2.94 \%)$.

Second, Table 5 reports the main results of interest in this study (Eq. 1). The maximum VIF factor is 9.02 and the adjusted $\mathrm{R}$ squared is $59.9 \%$. The probit residual is significant ( $\rho=-.005 ; p<.01)$, underscoring the importance of using an auxiliary regression to control for the endogenous nature of the health symbol addition decision.

Overall effect of a health symbol addition and interplay with perceived category healthiness Given that all continuous variables are mean-centered, and that all dichotomous variables are effect coded, the Addition variable gives an indication of the performance impact across the average of all moderating predictors, for an "average product" in an "average category," As expected, and in line with the model-free evidence and previous research (Dubois et al., 2021; Nikolova \& Inman, 2015), we find the main effect of adding a health symbol on product sales to be positive and significant $\left(\beta_{1}=.121, p<.01\right)$, and we find that this effect is significantly larger in healthier than in unhealthier categories $\left(\beta_{5}=.460, p<.01\right)$.

Interplay with taste claim, lower price and private label The sales impact of adding a health symbol depends on the presence of a front-of-package taste claim, the product's price, and 
on whether it concerns a private label product. We find the effects to be significantly larger in the presence of a taste claim $\left(\beta_{2}=.149, p<.01\right)$, for lower priced products $\left(\beta_{3}=.035\right.$, $p<.05)$, and for private label products $\left(\beta_{4}=.130, p<.01\right)$, thereby confirming $\mathrm{H} 1, \mathrm{H} 2$, and $\mathrm{H} 3$, respectively. This is in line with our reasoning and hypotheses that the addition of the health symbol disconfirms lay beliefs that products with a taste claim (tasty $=$ unhealthier), lower price (cheaper = unhealthier), or private label products (private label $=$ unhealthier) are overall not among the healthier products within the category.

Interplay of perceived category healthiness with taste claim, lower price and private label The positive impact for products with a taste claim and for private label products is contingent on the healthiness of the category, as indicated by the threeway interaction terms. More specifically, the positive moderating effect for products with a taste claim and for private label products (i.e., the positive effect of a health symbol addition

Table. 5 Results: Product sales (Eq. 1)

\begin{tabular}{|c|c|c|}
\hline Variable & Estimate & $\mathrm{SE}$ \\
\hline Addition $\left(\beta_{1}\right)$ & $.121 * * *$ & .028 \\
\hline$\times$ Taste claim $\left(\beta_{2}\right)$ & $.149 * * *$ & .014 \\
\hline$\times$ Lower price $\left(\beta_{3}\right)$ & $.035 * *$ & .014 \\
\hline$\times$ Private label $\left(\beta_{4}\right)$ & $.130 * * *$ & .019 \\
\hline$\times$ Perceived category healthiness $\left(\beta_{5}\right)$ & $.460 * * *$ & .079 \\
\hline$\times$ Taste claim $\times$ Perceived category healthiness $\left(\beta_{6}\right)$ & $.432 * * *$ & .061 \\
\hline$\times$ Lower price $\times$ Perceived category healthiness $\left(\beta_{7}\right)$ & .012 & .046 \\
\hline$\times$ Private label $\times$ Perceived category healthiness $\left(\beta_{8}\right)$ & $.200 * * *$ & .057 \\
\hline \multicolumn{3}{|l|}{ Control variables } \\
\hline Health symbol penetration $\left(\beta_{9}\right)$ & $.014 * * *$ & .003 \\
\hline Addition $\times$ Health symbol penetration $\left(\beta_{10}\right)$ & -.018 & .015 \\
\hline Addition $\times$ Basic category $\left(\beta_{11}\right)$ & -.009 & .021 \\
\hline Addition $\times$ Nutrition claim $\left(\beta_{12}\right)$ & $.068 * * *$ & .011 \\
\hline Relative regular price $\left(\beta_{13}\right)$ & $.146^{* * *}$ & .030 \\
\hline Relative feature-display intensity $\left(\beta_{14}\right)$ & $.139 * * *$ & .016 \\
\hline Relative price promotion $\left(\beta_{15}\right)$ & $.283 * * *$ & .036 \\
\hline Relative distribution $\left(\beta_{16}\right)$ & $.726 * * *$ & .044 \\
\hline Trend $\left(\beta_{17}\right)$ & $-.001 * * *$ & .000 \\
\hline Relative regular price - Copula & $-.147 * * *$ & .028 \\
\hline Relative feature-display intensity - Copula & $.073 * * *$ & .011 \\
\hline Relative price promotion - Copula & $-.111 * * *$ & .025 \\
\hline Relative distribution - Copula & $-.366 * * *$ & .036 \\
\hline Probit residual & $-.005 * * *$ & .001 \\
\hline Intercept $\left(\beta_{0}\right)$ & $1.371 * * *$ & .338 \\
\hline
\end{tabular}

$* * * p<.01 . * * p<.05 . * p<.10$. (two-sided)

All VIF values are below $10(M A X=9.02) ;$ Adj. $R^{\wedge} 2=.599 ; A R(1)=.638$ is stronger for products carrying a taste claim and private label products) is significantly stronger in healthier than in unhealthier categories $\left(\beta_{6}=.432, p<.01 ; \beta_{8}=.200\right.$, $p<.01$, respectively), confirming $\mathrm{H} 4$ and H6. The effect for lower priced products is also more positive in healthier than in unhealthier categories, but is insignificant $\left(\beta_{7}=\right.$ $.012, p=.79$ ). A simple slope analysis further reveals that the three product characteristics have a significant impact in both healthier and unhealthier categories (see Fig. 3 for details on the analysis and a visualization of the effects).

Control variables The main findings for the control variables show that the positive sales impact of adding a health symbol is not significantly reduced by incumbent products adding the health symbol as well $(\beta=-.018, p=.24)$, that there is no difference between basic and non-basic categories ( $\beta=-.009, p=.66)$, and that adding a health symbol is more impactful when the product faces a nutrition claim $(\beta=.068$, $p<.01$ ). Additionally, product sales go down when the relative price decreases $(\beta=.146, p<.01)$, and product sales go up when relative feature/display intensity increases $(\beta=.139$, $p<.01)$, relative price promotion increases $(\beta=.283$, $p<.01)$, and relative distribution increases $(\beta=.726$, $p<.01)$. All corresponding copula terms turned out significant ( $p$-values $<.01)$. Please see Table 5 for detailed results on all control variables included in the model.

\section{Robustness check: endogeneity}

To test to which extent our results are driven by our endogeneity corrections, we re-estimated our model three times: by (i) dropping the copula correction terms, (ii) dropping the control function correction term, and (iii) dropping the copula correction terms ánd the control function correction term. However, we find that our conclusions remain unchanged. As a further robustness check, we also estimated Eq. 1 without both the marketing mix variables and the corresponding copula terms. Again, our conclusions remain the same.

\section{Follow-up analyses}

Impact on primary demand It could be that the addition of a health symbol does not only affect the sales of the focal product, but also total sales of the category. For instance, front-ofpack nutrition claims can lead consumers to hold more positive attitudes towards the category and to have a greater willingness to buy (Talati et al., 2016). A potential negative consequence of these changed attitudes is increased consumption of unhealthy food (Cleeren et al., 2016; Talati et al., 2016). This may be particularly relevant in our setting, as we study a health symbol program that uses category-specific criteria. To 


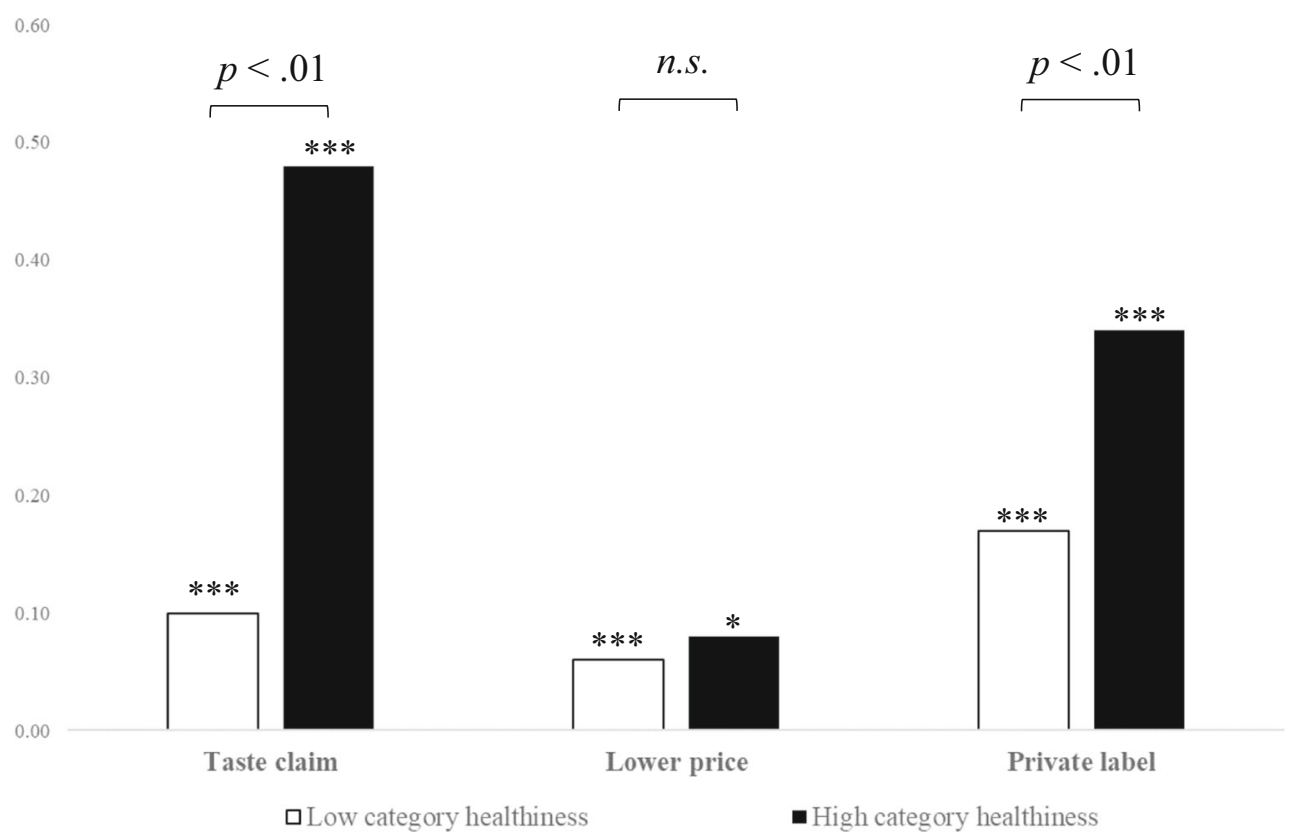

Fig. 3 Simple slope analyses of moderating effect of product characteristics on sales in healthier versus unhealthier categories $* * * p<.01 . * * p<.05 . * p<.10$. (two-sided).

Notes: Following Cohen et al. (2003), we calculate the slope and associated significance level of each product characteristic (i.e., taste claim, lower price, and private label) at lower (one standard deviation below the mean) and higher (one standard deviation above the mean) values of perceived category healthiness.

provide insight in potential primary demand changes, we regress the (ln-transformed) weekly category sales (across all products from all brands) against the (time specific) health symbol penetration within the category (i.e., $\%$ of products carrying a health symbol). To assess whether there are differences between healthier and unhealthier categories, we extend the regression with an interaction term between health symbol penetration and category healthiness. As control variables, we include category fixed effects, the same marketing mix variables from Eq. 1 (i.e., weighted category-level averages, using average product market shares across our sample as weights), marketing mix copula's to account for the marketing mix endogeneity, a copula term to account for the endogeneity of health symbol penetration, a deterministic trend, and an autoregressive residual. The results indicate no significant change in category sales as the penetration of health symbol use increases over time ( $\beta=-.018, p=.95)$. Moreover, the effect does not differ depending on the (un)healthiness of the category $(\beta=-.197, p=.45)$.

Impact on products not carrying a health symbol To provide insights into the source of gains for products adding the health symbol, we replaced total weekly category sales (as used in the first follow-up analysis) with (i) total weekly category sales from products that are not eligible to use the health symbol and (ii) total weekly category sales from products that

Read as follows: The moderating impact of taste claim and private label on the sales impact of the health symbol addition is significant in categories both low and high in healthiness $(p<.01)$, but is stronger in healthier than in unhealthier categories $(p<.01)$. The moderating impact of lower price is significant in categories with lower healthiness $(p<.01)$, as well as in categories with higher category healthiness $(p<.10)$, but the moderating impact of lower price does not differ significantly between healthier and unhealthier categories $(p>.10)$.

are eligible to use the health symbol but chose not to do so without our sample period. The results indicate that both eligible products $(\beta=-.163, p<.01)$ and non-eligible products $(\beta=-.191, p<.01)$ lose sales. Moreover, the size of the negative impact of category health symbol penetration on incumbent products does not significantly differ between eligible vs. non-eligible products $(\mathrm{z}=.69, p>.10$, see Paternoster et al., 1998 and Kumar et al., 2015 for a similar test). Hence, products without a health symbol lose sales after a health symbol addition within their category, irrespective of whether they qualify for the health symbol. We elaborate further on these findings in the Discussion.

\section{Discussion}

\section{Summary}

Manufacturers adopt health symbols to meet increasing consumer interest in healthier foods and to make finding a healthy product an easier task for consumers. This research studies the impact of adding a front-of-pack health symbol, signaling that the product is a healthier option within the category, on product sales. Using retailer sales data on 29 food product categories, we investigate how the sales impact of a health symbol differs in function of perceived category healthiness and the 
presence of a taste claim, lower price, and whether the product is a private label product.

Our empirical work on the heterogeneous impact of health symbol additions across products results in a number of novel findings. First, a product with a taste claim benefits more from adding a health symbol than a product without a taste claim. Products with taste claims are perceived as unhealthier than products without taste claims within the category (Howlett et al., 2009; Raghunathan et al., 2006), and the addition of the health symbol offers products with taste claims a way to counter this lay belief. Second, a product with a lower price within the category benefits more from adding a health symbol than a product with a higher price. Cheaper products are perceived as unhealthier than more expensive products within the category (Haws et al., 2017). Again, the addition of the health symbol can offset this belief, leading to a more positive impact of health symbol additions for lower priced products. Third, private label products benefit more than national brand products. This provides support for the reasoning that private label products are not perceived as the healthiest products within a category. Fourth, we find that these disconfirmation effects are more likely to occur in healthier than in unhealthier categories. The more positive impact for products with (vs. without) a taste claim and private label (vs. national brand) products, is more prevalent in healthier than in unhealthier categories. This can be related to the importance of the disconfirmed attribute (i.e., healthy) (Evangelidis \& Van Osselaer, 2018), as health is more important to consumers in healthier than in unhealthier categories (Dhar \& Wertenbroch, 2000; Wertenbroch, 1998).

Taken together, these results provide support for the hypothesis that health symbols are more effective in the presence of lay beliefs about a product's relative (un)healthiness that can be countered by the addition of a health symbol. These findings are in line with expectancy-disconfirmation theory, which posits that new information is especially effective in cases of disconfirmation (Oliver, 1980). In such instances, these lay beliefs can be positively disconfirmed by the addition of the health symbol, and we find that this affects consumers' purchase behavior, as the increase in performance is stronger in cases of positive disconfirmation. Furthermore, our finding that the impact on purchase behavior following positive disconfirmation is larger in healthier than unhealthier categories is in line with prior research showing that the effects of positive disconfirmation have more impact on consumer behavior when the underlying attribute is more important (Evangelidis \& Van Osselaer, 2018).

\section{Implications for manufacturers and public policy}

For manufacturers, our results imply that marketing the healthfulness of a product using health symbols will increase product performance especially when their product may not be perceived to be among the healthiest products within the category. Manufacturers should use a health symbol when they seek to signal the healthfulness of their products, in particular when they already contain a taste claim and when they are lower priced within the category. Marketing healthy and tasty simultaneously can be an opportunity for growth, and combining the health symbol with a taste claim may help overcome the lay belief that tasty products are less healthy. Similarly, marketing the healthfulness of lower priced products via a health symbol can overcome the lay belief that lower priced products are less healthy. Additionally, for retailers, our results imply that they can use health symbols to indicate that their products can nutritionally be among the best products in the category. Furthermore, our finding that an eligible, healthier, product without a health symbol is harmed to the same extent as a non-eligible, unhealthier, product suggests that deciding not to add a health symbol makes a product vulnerable to competing products that do add the health symbol. In summary, manufacturers or retailers that have products that are subject to lay beliefs leading consumers to believe the product is not healthier should provide information that stops consumers from relying on their lay theories, and our study shows health symbols can help do that. However, they should keep in mind that that the effects will be more pronounced in healthier than in unhealthier categories, where consumers attach more importance to health.

From a public policy perspective, our study shows first of all that a health symbol with category-specific criteria can help consumers in identifying the healthier options within a category, leading to a switch to the healthier alternatives within the category, without boosting category sales. Second, our results indicate that a health symbol can be a helpful tool to reduce reliance on potentially misleading lay beliefs among consumers such as that tastier and cheaper products are unhealthier.

Overall, our findings are also particularly relevant for countries either using health symbol programs with category-specific criteria (e.g., Singapore, Czech Republic, Malaysia, Indonesia) or planning to introduce a category-specific health symbol program (e.g., China). The use of category-specific criteria may be particularly helpful to create positive disconfirmation, whereas the use of cross-category criteria may categorize most products as relatively unhealthy in an unhealthy category. ${ }^{14}$ The more a

\footnotetext{
${ }^{14}$ Dubois et al. (2021) study a cross-category health symbol and find its effectiveness to be more pronounced in categories with more withincategory variation in healthiness, whereas Nikolova and Inman (2015) do not find an effect of within-category variation in healthiness. When we include this variable in our analysis (within-category variation in perceived category healthiness), we do not find an effect. A potential explanation may lay in the fact that both NuVal scores (ranking food products on 100-point scale) (used in Nikolova \& Inman, 2015) and the Choices health symbol (signaling the healthiness products within a category) in the current study may be more likely to allow consumers to identify relatively healthier options within a category with relatively little within-category variation. Nutri-Scores (ranking food products on a 5-point scale) (used in Dubois et al., 2021) may label all products as relatively comparable in terms of healthiness within categories with little within-category variation in product healthiness.
} 
health symbol signals within-category differences in healthiness (through mass communication and/or symbol design) the more likely consumers will perceive it as an indicator of withincategory product healthiness, potentially leading to stronger positive disconfirmation than a cross-category symbol. For instance, cross-category Nutri-Scores impact purchases of the healthiest products, but had little impact on purchases of food with medium or low nutrition quality (Dubois et al., 2021), whereas the category-specific health symbol, studied here, also leads to positive disconfirmation effects in unhealthy categories. That is, consumers buy the same volume of products within the category (i.e., category sales remain unaffected), but switch to the relatively healthier alternatives within the category that feature the health symbol. Still, the positive disconfirmation effects of using a (category-specific) health symbol remain more pronounced in healthier categories than in unhealthier categories, as health is more important to consumers in healthier than in unhealthier categories. As such, the importance consumers attach to health remains key to maximize the effectiveness of health symbol programs, which may be achieved more easily in healthier than in unhealthier categories.

Furthermore, it is important to ensure that consumers understand that a category-specific health symbol signals healthiness within a category (and not across categories) to avoid undesirable consumer behaviour (e.g., consumers purchasing more in unhealthier categories). A small-scale experiment (see Research Setting section and Appendix) suggests that our focal health symbol was indeed interpreted as a categoryspecific symbol. Communication about the meaning of cross-category health symbol programs likely also matters, as consumers do not seem to have strong views on whether (cross-category) Nutri-Scores signal within- or acrosscategory healthiness (see Fig. 4 in Appendix).

In sum, the addition of a health symbol can result in (i) an increase in product performance for the manufacturer of the product and (ii) consumers being better informed about the overall healthiness of grocery products within a category through an easy-to-process symbol. The category-specific health symbol serves as a helpful tool for consumers to choose a relatively healthier alternative. While ideally, from a consumer welfare perspective, one would not want consumers to buy in the unhealthier categories at all, the category-specific health symbol can offer consumers a relatively healthier alternative when they decide to buy in a specific (healthy or unhealthy) category.

\section{Limitations and future research}

Generalization To answer our research questions, we study a category-specific health symbol that summarizes overall product healthiness (i.e., across nutrients). The question remains whether our findings generalize towards programs that (i) are nutrient specific (e.g., Multiple Traffic Lights) and (ii) use cross-category criteria (e.g., Nutri-Scores). The underlying theorizing in our study is that health symbols are particularly effective when they positively disconfirm pre-existing lay beliefs. Conceptually, one could reasonably expect this effect to generalize to any type of health symbol that is able to positively disconfirm lay beliefs about a product's healthiness. However, it is unclear to which degree other types of symbols are effective in positively disconfirming lay beliefs. For example, nutrient-specific programs may be less likely to lead to positive disconfirmation because they still require consumers to assess and compare overall product healthiness themselves. Overall, the meta-analytic study by Ikonen et al. (2020) indicates that health symbols summarizing product healthiness across nutrients are more successful to help consumers identify healthier options than nutrient-specific programs. Similarly, positive disconfirmation may also be more pronounced for health symbols using category-specific criteria versus those using cross-category criteria, particularly in unhealthier product categories. This is because the use of cross-category criteria is less likely to lead to positive disconfirmation if all products within a category are labeled as unhealthy (e.g., crisps with a red traffic light). Future research can explore the role of disconfirmation for different types of health symbol programs.

Packaging change In our empirical analysis, we implicitly assume that at the time of the symbol addition the product remains the same and, hence, other packaging claims or symbols were added prior to the health symbol addition. However, it could be that manufacturers do not only add the health symbol, but simultaneously change another aspect of the packaging. ${ }^{15}$ Future research can explore in more detail to which degree manufacturers adjust packaging characteristics in response to health symbol programs.

Impact on products not carrying a health symbol In our sample, a substantial part of eligible products decided to not add the health symbol. A follow-up analysis indicates that eligible products without health symbols are equally harmed by health symbol additions in their category as products that do not meet the health criteria, thereby making eligible products (i.e., relatively healthier products within their category) vulnerable to lose sales to products that did decide to add it to their package.

\footnotetext{
$\overline{15}$ To gain a better insight in the simultaneity of packaging changes, we conducted an extensive online search for all 189 products in our dataset to recover images of the packaging with and without the health symbol. For 42 out of 189 products, we were able to recover an image of the product package without the symbol. For $90 \%$ (38 out of 42 products), packaging characteristics did not differ between the version with and without the health symbol, which suggests that at the time of the health symbol addition no other claims were added or removed. For the remaining $10 \%(N=4)$ we observe the following differences: the addition of a taste claim $(N=1)$, the removal of a taste claim $(N=1)$, and the addition of a nutrition claim and taste claim $(N=2)$. We tested the robustness of our findings by dropping these four observations. This does not alter our key findings.
} 
This suggests that consumers do not seem to be well informed about the healthiness of products without the health symbol, which would be required to determine whether a product without the health symbol voluntarily decided not to add the symbol, or whether the product does not meet the criteria. Future research should investigate perceptions among consumers about the healthiness of products without the health symbol, which is particularly relevant because in Europe, for instance, mandatory implementation of front-of-pack health symbols has not been possible from a legal perspective (Egnell et al., 2020). This means that even if a country decides to adopt a health symbol program (e.g., Nutri-Scores or Choices), the actual symbol addition decision is made by manufacturers themselves. However, it is not clear to what extent consumers view health symbol additions as optional vs. mandatory. Hence, future research should investigate the impact of health symbol programs being perceived as voluntary versus mandatory. On the one hand, consumers perceiving the symbol to be voluntary, may be less likely to draw conclusions about the healthiness of products without the health symbol. On the other hand, consumers may view products that add health symbols voluntarily (vs. mandatorily) as more positively, resulting in stronger negative effects for those not adding the symbol. For instance, in a restaurant context, Berry et al. (2018) assess the effect of restaurants voluntarily versus mandatorily providing menu calorie labelling, showing that the positive effects on attitudes toward the label-adding restaurant and its patronage disappear in a mandatory setting. In summary, future research should further study the impact of health symbol additions in the category on products without the health symbol and its underlying drivers.

Consumer heterogeneity While our dataset gives indications about overall product performance, it does not allow to account for differences between consumers. First, the importance of health may not only differ between categories, but may also depend on the consumer. Differences in the importance of health to consumers may therefore moderate the effectiveness of health symbols (Burton \& Kees, 2012; Trudel et al., 2015). Consumers who perceive the health consequences of not choosing the healthiest products to be large, may be more willing to switch purchases to products with a health symbol. Segmentation research has for instance indicated that consumers vary in the degree to which they find health important. For example, Trivedi and colleagues (2016) show that there is a "health driven" segment that finds health particularly important and accounts for $31 \%$ of consumers. Similarly, Verhoef and van Doorn (2016) identify a "health label" segment $(33 \%)$ that spends more on products with health claims and symbols than the average consumer. A similar view is (theoretically) proposed by Wansink (2017), arguing that there is a hierarchy of health predisposition among consumers, and that only a subset of consumers is expected to be "health vigilant." Future research could address how health symbol programs affect consumers with different health predispositions. Second, not all consumers may hold lay beliefs to the same extent. The effects are likely to be more prevalent among consumers who report to believe that product related aspects such as taste claims and a lower price are correlated with healthiness. Third, our health symbol flags healthier options in both healthy and unhealthy category, and does not decrease category demand in unhealthy categories at the aggregate level (i.e., across consumers). Further consumer research should study whether a category-specific health symbol could induce a false sense of healthy eating for unhealthy products among (some) consumers, as was the main criticism and cause for termination of the health symbol program in the Netherlands. Fourth, the assortment composition of the store(s) a consumer visits might influence consumer perceptions on what constitutes a lower priced product and thus influence a consumer's lay beliefs and, as such, health symbol effectiveness.

Profit implications Implementing the health symbol requires an investment from the manufacturer. For example, there is a cost to adjust product packaging when adding the health symbol, and participation in health symbol programs is typically not free of charge, which may lower the product's unit profit margin. Future research with access to data on the manufacturer's profit margins, can investigate the impact of adding a health symbol on overall profits.

\section{APPENDIX}

\section{Experimental study on consumer perceptions of the within-category designation of the health symbol.}

The aim of this study is to address how consumers interpret the "within-category" designation of our focal health symbol.

Design, measures, and sample We conducted a betweensubjects experiment with two conditions: (1) a categoryspecific health symbol condition, and (2) a cross-category health symbol condition, where participants were randomly assigned to a condition. The design of the category-specific symbol is based on the Choices symbol in our main study, and indicates that the product was a "Healthier choice within this product group" or "Conscious choice within this product group." For the cross-category symbol the Nutri-Score is chosen, which was recently selected as the successor of the Choices symbol in the Dutch market. The Nutri-Score has been launched throughout several European countries and was investigated in prior research (Dubois et al., 2021). The Nutri-Score is based on a five-colour coded scale going from 
Table. 6 Product Images

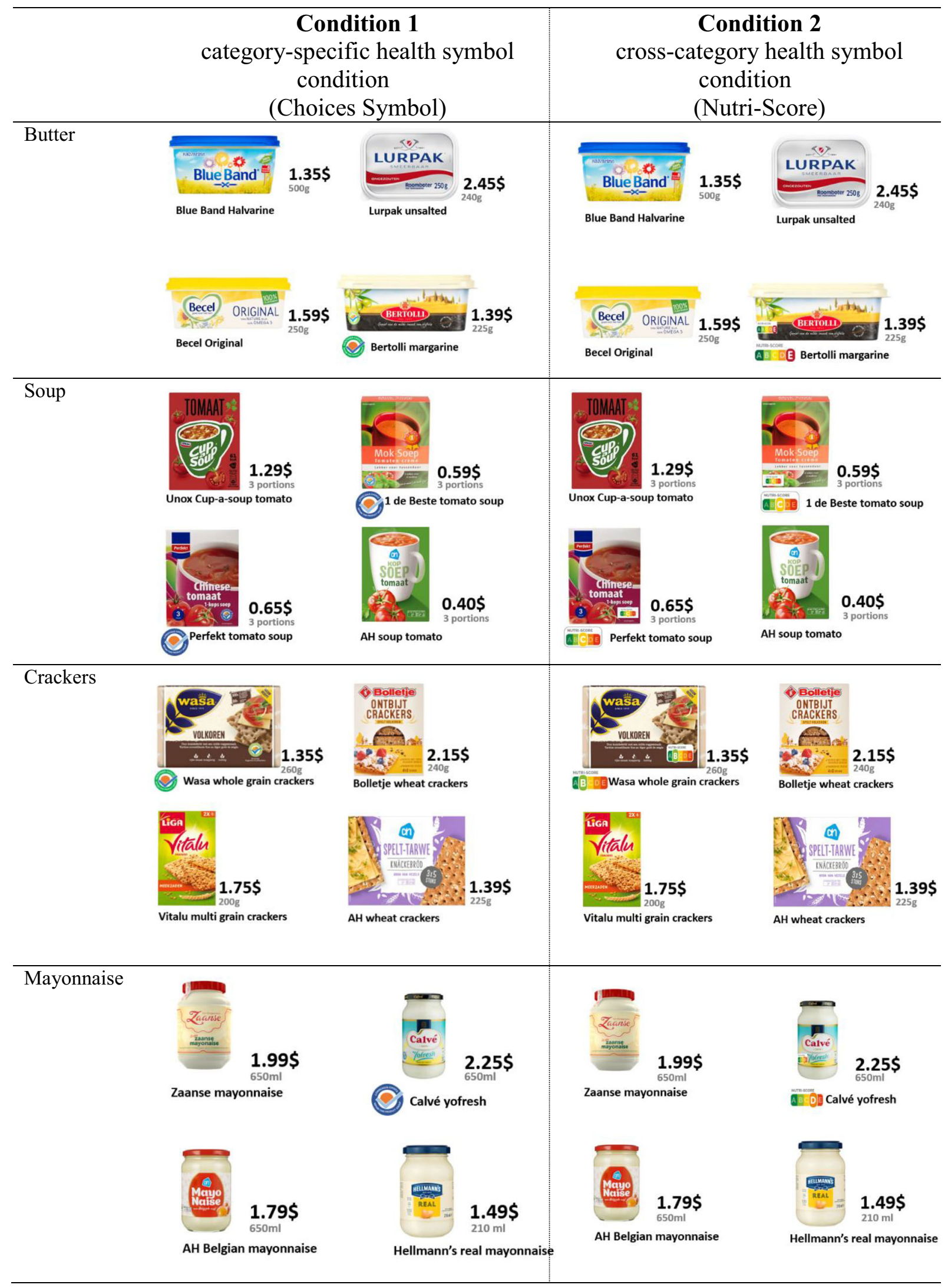


dark green (i.e., the best nutritional quality) to dark orange (i.e., the lowest nutritional quality), associated with letters from $\mathrm{A}$ to $\mathrm{E}$, and determined irrespective of the category. Four categories were selected: a more healthy, non-basic category (i.e., soup), a more healthy, basic category (i.e., crackers), a less healthy, non-basic category (i.e., mayonnaise) and a less healthy, basic category (i.e., butter). For each category (presented in a randomized order), participants were exposed to four product alternatives offered in the Dutch market where one product (in the categories crackers, mayonnaise and butter) or two products (in the category soup) carried a health symbol. Appendix Table 6 illustrates the product images used in both conditions. Apart from the health symbol, the product images are identical in both conditions.

To stimulate respondents to inspect the products, the respondents were first asked to select for each category which product they considered most attractive to purchase. After seeing products from all four categories, and after receiving a general definition of a category (i.e., that it refers to the group of products that the product belongs to), participants were asked to evaluate the health symbol they just saw on some of the products. Specifically, they answer the following 7-point Likert scale questions ( 1 = disagree, 7 = agree): (i) "I believe that the health label evaluates healthiness of the product within its own category of products" and (ii) "I believe that the health label evaluates healthiness of the product across all categories, including products outside its own category", related to the perceived "within-category" designation and the "cross-category" designation of the health symbol, respectively.

Our sample consists of 151 adult U.S. participants recruited via Amazon's Mechanical Turk (MTurk) (i.e., 77 in the category-specific condition and 74 in the cross-category condition). Participant's mean age was $43(\mathrm{SD}=11.87)$, and 54 $(46 \%)$ of the participants were male (female).

Results As shown in Fig. 4, perceived within-category designation is significantly higher among participants exposed to

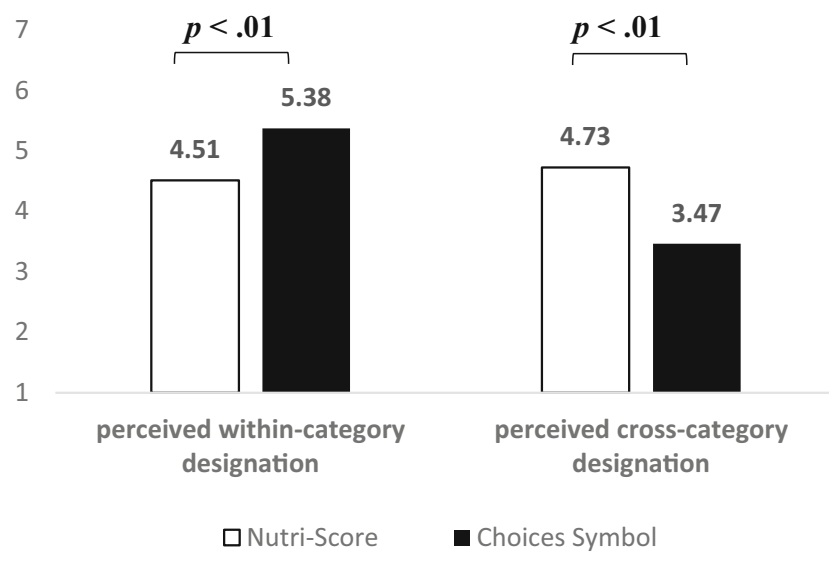

Fig. 4 Perceptions on the within-category and cross-category designation the category-specific health symbol $(\mathrm{M}=5.38, \mathrm{SD}=1.57)$ than the cross-category health symbol $(\mathrm{M}=4.51, \mathrm{SD}=$ $1.86)(t(149)=3.08, p<.01)$. On the other hand, the perceived cross-category designation is significantly higher for the cross-category health symbol condition $(M=4.73$, $\mathrm{SD}=1.69)$ compared to the category-specific health symbol $(\mathrm{M}=3.47, \mathrm{SD}=2.09)(t(149)=3.83, p<.01)$. This result provides empirical support for the notion that our focal category-specific health symbol is more likely to improve consumers' perception of the within-category healthiness of the product compared to a cross-category health symbol, whereas the cross-category health symbol is more likely to improve consumers' perceptions of the cross-category healthiness of the product compared to a category-specific health symbol.

Acknowledgements We gratefully acknowledge financial support from the Flemish Organization for Scientific Research (FWO) and from Internal KU Leuven Funds. We thank the Choices Foundation and the "PS in Foodservice" organization for providing data. We also thank participants at the 2015 EMAC Doctoral Colloquium, the 2016 and $2017 \mathrm{KU}$ Leuven-Groningen research seminars, the 2017 EMAC Conference, and the 2017 Marketing Dynamics Conference.

Author's contribution Léon Jansen contributed to the paper by providing data and insights into the research setting.

Open Access This article is licensed under a Creative Commons Attribution 4.0 International License, which permits use, sharing, adaptation, distribution and reproduction in any medium or format, as long as you give appropriate credit to the original author(s) and the source, provide a link to the Creative Commons licence, and indicate if changes were made. The images or other third party material in this article are included in the article's Creative Commons licence, unless indicated otherwise in a credit line to the material. If material is not included in the article's Creative Commons licence and your intended use is not permitted by statutory regulation or exceeds the permitted use, you will need to obtain permission directly from the copyright holder. To view a copy of this licence, visit http://creativecommons.org/licenses/by/4.0/.

\section{References}

Alba, J. W., \& Broniarczyk, S. M. (1994). The role of consumers' making intuitions in inference. Journal of Consumer Research, 21(3), 393407.

Andrews, J. C., Lin, C.-T. J., Levy, A. S., \& Lo, S. (2014). Consumer research needs from the Food and Drug Administration on front-ofpackage nutritional labeling. Journal of Public Policy \& Marketing, $33(1), 10-16$.

Arora, S., ter Hofstede, F., \& Mahajan, V. (2017). The implications of offering free versions for the performance of paid. Journal of Marketing, 81(6), 62-78.

Ataman, M. B., Van Heerde, H. J., \& Mela, C. E. (2010). The long-term effect of marketing strategy on brand sales. Journal of Marketing Research, 47(5), 866-882.

Balasubramanian, S. K., \& Cole, C. (2002). Consumers' search and use of nutrition information: The challenge and promise of the nutrition labeling and education act. Journal of Marketing, 66(3), 112-127. 
Berning, J. P., Chouinard, H. H., \& McCluskey, J. J. (2008). Consumer preferences for detailed versus summary formats of nutrition information on grocery store shelf labels. Journal of Agriculture \& Food Industrial Organization, 6(1), 1-35.

Berry, C., Burton, S., \& Howlett, E. (2018). The effects of voluntary versus mandatory menu calorie labeling on consumers' retailerrelated responses. Journal of Retailing, 94(1), 73-88.

Boston Consultancy Group (2016). How Healthy Foods are Nourishing Growth in the CPG Industry, (April 2016), available at https://www. bcgperspectives.com/content/articles/consumer-productsinnovation-how-healthy-foods-are-nourishing-growth-cpgindustry/. Accessed 28 June 2017.

Burke, P. F., Eckert, C., \& Sethi, S. (2020). A multiattribute benefitsbased choice model with multiple mediators: New insights for positioning. Journal of Marketing Research, 57(1), 35-54.

Burton, S., \& Kees, J. (2012). Flies in the ointment? Addressing potential impediments to population-based health benefits of restaurant menu labeling initiatives. Journal of Public Policy and Marketing, 31(2), 232-239.

Burton, S., Cook, L. A., Howlett, E., \& Newman, C. L. (2015). Broken halos and shattered horns : Overcoming the biasing effects of prior expectations through objective information disclosure. Journal of the Academy of Marketing Science, 43(2), 240-256.

Choices Program (2019). Asian Experience With Positive Front of Pack Labeling, (October 2019), available at https://www. choicesprogramme.org/news-updates/news/asian-experience-withpositive-front-of-pack-labelling. Accessed 18 June 2020.

Cleeren, K., Geyskens, K., Verhoef, P. C., \& Pennings, J. M. (2016). Regular or low-fat? An investigation of the long-run impact of the first low- fat purchase on subsequent purchase volumes and calories. International Journal of Research in Marketing, 33(4), 1-33.

Cohen, J., Cohen, P., West, S. G., \& Aiken, L. S. (2003). Applied multiple regression/correlation analysis for the behavioral sciences (3rd ed.). Erlbaum.

Consumentenbond (2016). Resultaten Panelonderzoek het Vinkje, (March 2016), available at https://www.consumentenbond.nl/ binaries/content/assets/cbhippowebsite/actie-voeren/vinkjes/ opmaak_resultaten_onderzoek_het_vinkje-v4b.pdf. Accessed 28 Aug 2019.

Consumer Reports (2010). Store Brands vs. Name Brands, NY: Consumer Reports Inc.

Danaher, P. J., Smith, M. S., Ranasinghe, K., \& Danaher, T. S. (2015). Where, when, and how long: Factors that influence the redemption of mobile phone coupons. Journal of Marketing Research, 52(5), 710-725.

Datta, H., Ailawadi, K. L., \& van Heerde, H. J. (2017). How well does consumer-based brand equity align with sales-based brand equity and marketing-mix response? Journal of Marketing, 81(3), 1-20.

Day, G. S., Shocker, A. D., \& Srivastava, R. K. (1979). Customeroriented approaches to identifying product-markets. Journal of Marketing, 43(4), 8-19.

Deloitte (2016). Capitalizing on the shifting consumer food value equation, available at https://www2.deloitte.com/content/dam/Deloitte/ us/Documents/consumer-business/us-fmi-gma-report.pdf. Accessed 31 July 2017.

Dhar, R., \& Simonson, I. (1999). Making complementary choices in consumption episodes : Highlighting versus balancing. Journal of Marketing Research, 36(1), 29-44.

Dhar, R., \& Wertenbroch, K. (2000). Consumer choice between hedonic and utilitarian goods. Journal of Marketing Research, 37(February), 60-71.

Dinner, I. M., van Heerde, H. J., \& Neslin, S. (2014). Driving online and offline sales: The cross-channel effects of digital versus traditional advertising. Journal of Marketing Research, 51(5), 527-545.

Distrifood (2016). Vinkje verdwijnt uit supermarkt, (October 2016), available at http://www.distrifood.nl/branche-bedrijf/nieuws/2016/ 10/vinkje-verdwijnt-uit-supermarkt-101102176. Accessed 10 Aug 2017.

Dubois, P., Albuquerque, P., Allais, O., Bonnet, C., Bertain, P., Combris, P., Lahlou, S., Rigal, N., Ruffieux, B., \& Chandon, P. (2021). Effects of front-of-pack labels on the nutritional quality of supermarket food purchases: Evidence from a large-scale randomized controlled trial. Journal of the Academy of Marketing Science, 49(1), 119-138.

Egnell, M., Talati, Z., Galan, P., Andreeva, V. A., Vandevijvere, S., Gombaud, M., Dréano-Trécant, L., Hercberg, S., Pettigrew, S., \& Julia, C. (2020). Objective understanding of the Nutri-score front-ofpack label by European consumers and its effect on food choices: An online experimental study. International Journal of Behavioral Nutrition and Physical Activity, 17(1), 1-13.

Evangelidis, I., \& Van Osselaer, S. M. J. (2018). Points of (dis)parity: Expectation disconfirmation from common attributes in consumer choice. Journal of Marketing Research, 55(1), 1-13.

Feunekes, G. I. J., Gortemaker, I. a., Willems, A. a., Lion, R., \& van den Kommer, M. (2008). Front-of-pack nutrition labelling: Testing effectiveness of different nutrition labelling formats front-of-pack in four European countries. Appetite, 50(1), 57-70.

Financial Times (2016). Big Food in Health Drive to Keep Market Share, (April 2016), available at https://www.ft.com/content/83f05ea808a3-11e6-a623-b84d06a39ec2?mhq5j=e2. Accessed 28 June 2017.

Food Navigator (2017). Goodbye NuVal... and good riddance?, (November 2017), available at https://www.foodnavigator-usa. com/Article/2017/11/13/Goodbye-NuVal-and-good-riddance. Accessed 24 June 2019

Furnham, A. (1988). Lay theories: Everyday understanding of problems in the social sciences. Pergamon.

Germann, F., Ebbes, P., \& Grewal, R. (2015). The chief marketing officer matters! Journal of Marketing, 79(May), 1-22.

Geyskens, I., Gielens, K., \& Gijsbrechts, E. (2010). Proliferating privatelabel portfolios: How introducing economy and premium private labels influences brand choice. Journal of Marketing Research, 47(5), 791-807.

Gielens, K., Geyskens, I., Deleersnyder, B., \& Nohe, M. (2018). The new regulator in town: The effect of Walmart' $\mathrm{s}$ sustainability mandate on supplier. Journal of Marketing, 82(2), 124-141.

Gijsenberg, M. J. (2014). Going for gold: Investigating the (non)sense of increased advertising around major sports events. International Journal of Research in Marketing, 31(1), 2-15.

Grunert, K., \& Wills, J. (2007). A review of European research on consumer response to nutrition information on food labels. Journal of Public Health, 15(5), 385-399.

Guitart, I. A., Gonzalez, J., \& Stremersch, S. (2018). Advertising nonpremium products as if they were premium : The impact of advertising up on advertising elasticity and brand equity. International Journal of Research in Marketing, 35(3), 471-489.

Haws, K. L., Reczek, R. W., \& Sample, K. L. (2017). Healthy diets make empty wallets: The healthy $=$ expensive intuition. Journal of Consumer Research, 43(6), 992-1007.

Heerde, V., Harald, J., Gijsenberg, M. J., Dekimpe, M. G., \& Steenkamp, J.-B. E. (2013). Price and advertising effectiveness over the business cycle. Journal of Marketing Research, 50(2), 177-193.

Howlett, E. A., Burton, S., Bates, K., \& Huggins, K. (2009). Coming to a restaurant near you? Potential consumer responses to nutrition information disclosure on menus. Journal of Consumer Research, 36(October), 494-503.

Hoyer, W. D., MacInnis, D. J., \& Pieters, R. (2013). Consumer behavior (6th ed.). Cengage Learning.

Ikonen, I., Sotgiu, F., Aydinli, A., \& Verlegh, P. W. J. (2020). Consumer effects of front-of-package nutrition labeling: An interdisciplinary meta-analysis. Journal of the Academy of Marketing Science, 48, 360-383. 
Iyengar, S. S., \& Lepper, M. R. (2000). When choice is demotivating : Can one desire too much of a good thing? When choice is demotivating : Can one desire too much of a good thing? Journal of Personality and Social Psychology, 79(6), 995-1006.

Jansen, L., \& Roodenburg, A. J. C. (2016). The use of food composition data in the choices international Programme. Food Chemistry, 193, 196-202.

Jo, J., \& Lusk, J. L. (2018). If it' s healthy, it's tasty and expensive: Effects of nutritional labels on price and taste expectations. Food Quality and Preference, 68, 332-341.

Judge, G. G., Hill, R. C., Griffiths, W. E., Lütkepohl, H., \& Lee, T.-C. (1988). Introduction to the Theory and Practice of Econometrics (2nd ed.). Wiley.

Keller, K. L. (1993). Conceptualizing, measuring, managing customerbased brand equity. Journal of Marketing, 57(1), 1-22.

Keller, K. O., Dekimpe, M. G., \& Geyskens, I. (2016). Let your banner wave? Antecedents and performance implications of retailers' private-label branding strategies. Journal of Marketing, 80(4), 1-19.

Kiesel, K., \& Villas-Boas, S. B. (2013). Can Information Costs Affect Consumer Choice? Nutritional Labels in a Supermarket Experiment. International Journal of Industrial Organization, 31(2), 153-163.

Kim, K., Cheong, Y., \& Zheng, L. (2009). The current practices in food advertising: The usage and effectiveness of different advertising claims. International Journal of Advertising, 28(3), 527-553.

Kumar, V., Bhagwat, Y., \& Zhang, X. (2015). Regaining "lost" customers: The predictive power of first-lifetime behavior, the reason for defection, and the nature of the win-back offer. Journal of Marketing, 79(4), 34-55.

Lamey, L., Deleersnyder, B., Steenkamp, J.-B. E., \& Dekimpe, M. G. (2012). The effect of business-cycle fluctuations on private-label share: What has marketing conduct got to do with it? Journal of Marketing, 76(1), 1-19.

Lim, L. G., Tuli, K. R., \& Dekimpe, M. G. (2018). Investors' evaluations of price-increase preannouncements. International Journal of Research in Marketing, 35(3), 359-377.

Luchs, M. G., Naylor, W., Rebecca, I., Julie, R., \& Raghunathan, R. (2010). The sustainability liability: Potential negative effects of ethicality on product preference. Journal of Marketing, 74(5), 18-31.

MacKenzie, S. B. (1986). The role of attention in mediating the effect of advertising on attribute importance. Journal of Consumer Research, 13(2), 174

Mai, R., \& Hoffmann, S. (2015). How to combat the unhealthy = tasty intuition: The influencing role of health consciousness. Journal of Public Policy \& Marketing, 34(1), 63-83.

Moorman, C. (1996). A quasi experiment to assess the consumer and informational determinants of nutrition information processing activities: The case of the nutrition labeling and education act. Journal of Public Policy \& Marketing, 15(1), 28-44.

Myers, J. H., \& Alpert, M. I. (1968). Determinant buying attitudes: Meaning and measurement. Journal of Marketing, 32(4), 13-20.

Nielsen (2012). A Nielsen Report: Battle of the Bulge and Nutrition Labels. Healthy Eating Trends Around the World, available at http://silvergroup.asia/wp-content/uploads/2012/02/NielsenGlobal-Food-Labeling-Report-Jan2012.pdf. Accessed 31 July 2017.

Newman, C. L., Howlett, E., \& Burton, S. (2014). Shopper response to front-of-package nutrition labeling programs: Potential consumer and retail store benefits. Journal of Retailing, 90(1), 13-26.

Nielsen (2017). Capitalizing on health and wellness trends: an opportunity for FMCG companies to partner with consumers, available at http://www.nielsen.com/content/dam/corporate/us/en/reportsdownloads/2017-reports/health-wellness-report-feb-2017.pdf. Accessed 31 July 2017.

Nikolova, H. D., \& Inman, J. J. (2015). Healthy choice: The effect of simplified POS nutritional information on consumer food choice behavior. Journal of Marketing Research, 52(6), 817-835.
Oliver, R. L. (1980). A cognitive model of the antecedents and consequences of satisfaction decisions. Journal of Marketing Research, 17(4), 460-469.

Papies, D., Ebbes, P., \& van Heerde, H. (2017). Addressing endogeneity in marketing models. In P. S. H. Leeflang, J. E. Wieringa, T. H. A. Bijmolt, \& K. H. Pauwels (Eds.), Advanced Methods for Modeling Markets (pp. 581-630). Springer.

Park, S., \& Gupta, S. (2012). Handling endogenous regressors by joint estimation using copulas. Marketing Science, 31(4), 567-586.

Paternoster, R., Brame, R., Mazerolle, P., \& Piquero, A. (1998). Using the correct statistical test for the equality of regression coefficients. Criminology, 36(4), 859-866.

Petrin, A., \& Train, K. (2010). A control function approach to endogeneity in consumer choice models. Journal of Marketing Research, 47(1), 3-13.

Raghunathan, R., Naylor, R. W., \& Hoyer, W. D. (2006). The unhealthy $=$ tasty intuition and its effects on taste inferences, enjoyment, and choice of food products. Journal of Marketing, 70(4), 170-184

Ramanathan, S., \& Menon, G. (2006). Time-varying effects of chronic hedonic goals on impulsive behavior. Journal of Marketing Research, 43(4), 628-641.

Rossi, P. E. (2014). Even the rich can make themselves poor: A critical examination of IV methods in marketing applications even the rich can make themselves poor: A critical examination of IV methods in marketing applications. Marketing Science, 33(5), 655-672.

Rutz, O. J., \& Watson, G. F. (2019). Endogeneity and marketing strategy research: An overview. Journal of the Academy of Marketing Science, 47(3), 479-498.

Shiv, B., Carmon, Z., \& Ariely, D. (2005). Placebo effects of marketing actions: Consumers may get what they pay for. Journal of Marketing Research, 42(4), 383-393.

Sotgiu, F., \& Gielens, K. (2015). Suppliers caught in supermarket Price wars: Victims or victors? Insights from a Dutch Price war. Journal of Marketing Research, 52(6), 784-800.

Sridhar, S., Germann, F., Kang, C., \& Grewal, R. (2016). Relating online, regional, and national advertising to firm value. Journal of Marketing, 80(4), 39-55.

Talati, Z., Pettigrew, S., Dixon, H., Neal, B., Ball, K., \& Hughes, C. (2016). Do health claims and front-of-pack labels lead to a positivity bias in unhealthy foods? Nutrients, 8(12), 1-18.

Trivedi, M., Sridhar, K., \& Kumar, A. (2016). Impact of healthy alternatives on consumer choice: A balancing act. Journal of Retailing, 92(1), 65-82.

Trudel, R., Murray, K. B., Kim, S., \& Chen, S. (2015). The impact of traffic light color-coding on food health perceptions and choice. Journal of Experimental Psychology: Applied, 21(3), 255-275.

Verhoef, P. C., \& van Doorn, J. (2016). Segmenting consumers according to their purchase of products with organic, fair-trade, and health labels. Journal of Marketing Behavior, 2(1), 19-37.

Vyth, E. L., Steenhuis, I. H. M., Mallant, S. F., Mol, Z. L., Brug, J., Temminghoff, M., Feunekes, G. I., Jansen, L., Verhagen, H., \& Seidell, J. C. (2009). A front-of-pack nutrition logo: A quantitative and qualitative process evaluation in the Netherlands. Journal of Health Communication, 14, 631-645.

Wansink, B. (2017). Healthy profits: An interdisciplinary retail framework that increases the sales of healthy foods. Journal of Retailing, 93(1), 65-78.

Wertenbroch, K. (1998). Consumption self-control by rationing purchase quantities of virtue and vice. Marketing Science, 17(4), 317-337.

Publisher's note Springer Nature remains neutral with regard to jurisdictional claims in published maps and institutional affiliations. 